Palimpsesto Vol. 11, No 19 (Julio-diciembre, 2021): 213-245

Universidad de Santiago de Chile, ISSN 0718-5898

\author{
Juan Pablo González Quezada \\ Universidad de Concepción \\ juan.gonzalez.quezada1992@gmail.com \\ Javiera Paulsen Contreras \\ Universidad Alberto Hurtado \\ paulsenjaviera@gmail.com \\ Constanza Sánchez Carvajal \\ Universidad Diego Portales \\ cony.9228@gmail.com
}

\title{
Debates y Reformas a las policías en Chile, Colombia y Ecuador: Un estudio comparativo
}

\section{Debates and Reforms to the Police in Chile, Colombia and Ecuador: A Comparative Study}

\begin{abstract}
Resumen
Chile, Colombia y Ecuador han experimentado una creciente demanda de reformas policiales por parte de la ciudadanía, surgidas luego de la respuesta policial ante masivas protestas ocurridas en los 3 países durante el año 2019. Esta investigación apunta a comparar los procesos de reforma policial en los tres países seleccionados, buscando elementos convergentes en los discursos con los que actores políticos han abordado las propuestas a las reformas policiales, contextualizándolas dentro de la historia de cada una de las instituciones que cumplen la función policial: Carabineros de Chile, Policía Nacional de Ecuador y la Policía Nacional de Colombia. Con esto pretendemos aportar al debate sobre la institucionalidad policial y los paradigmas desde los que se discute la seguridad ciudadana y el orden público sobre todo a raíz de las violaciones a derechos humanos presentes en los países por parte de la fuerza policial.
\end{abstract}

Palabras claves: Policías, Latinoamérica, Modernización, Reformas, Violaciones a Derechos Humanos.

\begin{abstract}
Chile, Colombia and Ecuador have experienced attempts of police reform in response to the need to generate change within these institutions. This research aims to identify the events that led to police reform processes in the three cases, generating a comparison between the processes and debates around police reforms, emphasizing common actors and socio-political processes to establish convergences and
\end{abstract}


differences in the reform processes. As well as contributing to a debate on police institutionality and the paradigms from which citizen security and public order are discussed, especially as a result of the human rights violations committed by the police in these countries.

Keywords: Police, Latin America, Modernization, Reform, Human Rights violations.

\section{Introducción}

La presente investigación corresponde a una comparación de los procesos de reformas de tres instituciones policiales latinoamericanas: Carabineros de Chile, la Policía Nacional de Ecuador y la Policía Nacional de Colombia.

En estos tres países, el proceso de reforma policial ha surgido como una necesidad ante diferentes problemas en las instituciones policiales. A pesar de que ocurren en contextos distintos, también ${ }^{1}$ forman parte de un desarrollo institucional común. Siguiendo la caracterización que hace Galeano (2007), estas tres policías se inscriben dentro de lo que él caracteriza como policías que surgieron subordinadas a las fuerzas armadas, las cuales conquistaron su autonomía entrado el siglo XX con un modelo centralizado que opera en todo el territorio nacional, modelo de desarrollo que es emblemático del continente.

Otro factor común entre estos países es que el debate actual acerca de la necesidad de reformas policiales se ha posicionado a raíz de las denuncias de violaciones masivas a los derechos humanos ocurridas en el marco de los estallidos sociales que marcaron a estos países desde el año 2019, y que fue un desencadenante para posteriores procesos políticos y sociales en cada nación. Dada la particularidad y la extensión de este debate en cada uno de los países seleccionados, cada fenómeno será comparado de manera asincrónica, para concentrarse fundamentalmente en las convergencias y divergencias de cada proceso.

Metodológicamente, para el desarrollo de este estudio se utilizó un enfoque comparativo desde una perspectiva multidisciplinaria analizando los procesos e intentos de reforma legal de las policías desde tres ejes: el primero es una caracterización histórica que permita la contextualización de estos procesos, identificando actores y reacciones sociales. La segunda se centra en los discursos respecto a dichas reformas por parte de actores clave con poder de decisión, en donde la cristalización de los conceptos y símbolos ideológicos motivan las diversas posturas frente a las reforma y por último, las características institucionales y estructurales de las policías que juegan un rol preponderante a la hora de hablar y delinear las reformas policiales. Es el diálogo entre estos elementos lo que nos permite comprender las características convergentes y divergentes que presentan los tres procesos abordados y poder comprender el por qué estos procesos - o intentos- de reformas responden a dinámicas similares.

\footnotetext{
${ }^{1}$ El autor cita expresamente como excepción a este modelo los casos de los países: Argentina, Brasil, México, Costa Rica y Venezuela.
} 


\section{Delimitaciones teóricas}

Es necesario presentar algunos conceptos necesarios para poder comprender de mejor manera nuestro objeto de estudio, que dan cuenta de los distintos procesos de transformación que han sufrido las instituciones policiales.

\section{a) Instituciones Policiales}

Para comenzar, es necesario definir a cada una de las instituciones policiales; de acuerdo con la definición que hace L. Dammert (2005), es posible reconocer tres elementos comunes en las policías. El primero de ellos, tiene que ver con el hecho de que las instituciones policiales detentan el monopolio del uso legítimo de la fuerza en un Estado de Derecho, es decir, a través del ordenamiento jurídico la institución adquiere la capacidad y las condiciones para hacer uso de la fuerza. En segundo lugar, es posible señalar que la fuerza que estas instituciones ejercen es pública; en otras palabras, la institución policial responde a las necesidades de la sociedad en su totalidad. Finalmente, se trata de fuerzas profesionales que cuentan con capacidad de instrucción para inculcar en sus funcionarios el uso de conocimientos y técnicas que apuntan al logro de los objetivos de la institución.

De acuerdo con esto, las instituciones policiales no solo se compondrían por los mandos definidos dentro de los escalafones, sino que también involucraría a los tres mandos civiles, es decir, aquellos definidos dentro de la legalidad como mandos no policiales, que no poseen carrera ni grado dentro del escalafón policial, pero que poseen responsabilidad y capacidad de decisión en los tres aspectos antes mencionados: el Ministro del Interior en Chile, el Ministro de Gobierno en Ecuador y el Ministro de Defensa en Colombia.

Es importante integrar, para esta discusión teórica, una característica particular dentro de las políticas de seguridad implementadas en América Latina: la línea entre las funciones del ejército y la de los policías es difusa, puesto que muchas veces el ejército realiza funciones que han sido definidas como policiales. Si bien constitucionalmente existe una diferencia, en la práctica los países recurren a mecanismos legales para "borrarlas":

Las respuestas más comunes al escalamiento percibido del crimen con violencia a través de la mayor parte de América Latina son el aumento del tamaño y los poderes de la policía local y — en la mayoría de los casos incrementar - la participación de las fuerzas armadas para enfrentar tanto al crimen común como al organizado. (Bailey, Parás \& Vargas López, 2013)

\section{b) Reformas y Modernizaciones}

Para abordar el objeto de estudio, es pertinente considerar la distinción teórica entre aquello que corresponde a una reforma y lo que no. De acuerdo con Dammert, la reforma policial en Europa y Norteamérica muestra importantes cambios en aspectos de la función y doctrina policial, mientras que en Latinoamérica las reformas se han orientado, sobre todo, hacia esfuerzos graduales para reorganizar a la policía, purgar a los oficiales corruptos y mejorar el reclutamiento 
y formación, así como también hacia el aumento de la vigilancia y participación de la sociedad civil (Dammert L., 2005, pp. 57-58).

En términos concretos, I. Badiola (2011), desarrolla dos ejes que deben cumplirse para hablar de una reforma: Answerability, es decir normativas orientadas a obligar a los funcionarios a informar y justificar sus decisiones ante poderes del civil, y Enforcement, que se asocia a normativas que otorgan la capacidad de sancionar a funcionarios en caso de que hayan violado o desatendido sus deberes públicos. Así mismo, O'Donnell (2002) permite establecer dos características claves en relación con la definición de una reforma policial: la horizontal, que se refiere a la existencia de mecanismos de control entre diferentes agencias del Estado en un sistema de equilibrios, y la vertical, que se relacionan con el control ejercido por la sociedad hacia el Estado, en la que las acciones policiales tienen consecuencias.

Estas dos conceptualizaciones permiten identificar dos modalidades que pueden adoptar las reformas policiales: Por un lado, tenemos elementos de las reformas institucionales que permiten a la sociedad civil tener acceso a la justificación detrás de las decisiones que toman las instituciones policiales, otorgándoles grados de incidencia, en esta modalidad podemos citar como ejemplo la "ley $\mathrm{N}^{\circ} 20.287$ de acceso a la información pública" en el caso de Carabineros de Chile, la cual faculta a cualquier ciudadano a solicitar información respecto a actuaciones por parte de funcionarios de la institución. Paralelamente, otra forma que pueden adoptar los intentos de reforma se da dentro de la misma institucionalidad entre el Estado, en donde otra institución estatal es quien recibe estas capacidades, como sucede con la creación del Consejo de Seguridad Pública y del Estado, mediante la Ley de Seguridad Pública y del Estado en Ecuador.

Sin embargo, estos términos no agotan las transformaciones institucionales que han sucedido dentro de las instituciones policiales, es aquí donde surge el concepto de modernización. Tal como señala la etimología de la palabra, "modernizar" alude a la transformación de la estructura y la forma de un objeto hasta el punto en que se convierte en un semejante a otros objetos modernos del mismo tipo. Si se tiene en cuenta esto la modernización, entonces, se aboca al proceso que se hace necesario para lograr esta modernidad mediante un proceso de transformación (Saboya Vargas, 2006, p. 363).

Néstor Legnani, en cuanto a la modernización policial, señala que el "rol de lo educativo - entendido como capacitación-es un aspecto central que posibilitará una reforma con continuidad, desprovista de espasmos de política pública temporaria” (Legnani, 2007). Existen otras medidas orientadas a la modernización policial cuyo foco está en el aumento de la eficacia de la gestión policial, además de llevar consigo una mejora en cuanto a los procedimientos administrativos. También existen otras que se orientan a reformas más profundas, con un horizonte de mediano y largo plazo, para lo que se hace necesario tener objetivos estratégicos y otros aspectos que tengan como meta el colaborar con un fin común (Kozma, 2014).

\section{c) Discursos y Actores}

Claudio Fuentes (2001) identifica un complejo escenario cuando los gobiernos deciden aplicar represión para cuidar la seguridad pública, también conocida como la "mano dura" es un discurso que impone cero tolerancia al crimen y a la delincuencia, sin embargo en diversas ocasiones los gobiernos de la región latinoamericana se ven tentados a usar la coerción en conflictos sociales, confundiendo esta última como delincuencia y violencia lo que termina 
convirtiéndose en violaciones por parte del estado a la integridad de los ciudadanos. Según el autor, los Estados democráticos deben crear un equilibrio entre la protección a los derechos humanos y la mantención de la seguridad pública. Sin embargo, los estados comúnmente mantienen la seguridad pública, creando más represión, entregando atribuciones a las policías, arrestando más ciudadanos, etc. En síntesis, la "mano dura" no otorga resultados efectivos, ya que el estado reprime a quien considere peligroso, y en muchas ocasiones no es para enfrentar el verdadero crimen y delincuencia.

\section{d) Opacidad}

Para poder acercarse al estudio dentro de las instituciones policiales y entender sus dinámicas, existe un concepto llamado opacidad la que se entiende como la resistencia que tiene una institución al ser observada, en el caso de las policías esto es un factor muy común, ya que los investigadores de cualquier área se encuentran con grandes trabas cuando se quiere recurrir a datos e información. El problema es que diversas disciplinas no han podido realizar investigaciones en profundidad por este obstáculo. problema:

Según Hathazy, (citado en Sirimarco, 2010) expone la postura de Sozzo, explicando este

En lugar de aceptar esta refracción simplemente como una constante de toda configuración social moderna, sugiero en primer lugar que estas específicas resistencias sean positivamente integradas al trabajo de producción empírica de manera consciente y en segundo lugar [...] utilizarlas como reveladoras de relaciones policia-politicaacademia. (Sirimarco, 2010, p. 146)

Siguiendo con la visión de Hathazy, (citado en Sirimarco, 2010), el problema de la opacidad se manifiesta en la relación de tres actores: la policía, la política y la academia. La policía y la política tienen una relación de complicidad en la que la obstrucción está tan aceptada por ambas instituciones que llegan a trabajar en conjunto para que cualquier irregularidad que ocurra se enmarque únicamente en el ámbito institucional. "En este caso la obstrucción es generada por agentes políticos y policiales y refleja una cultura policial que valora el secreto, el silencio y la simulación, todo ello anclado en última instancia en una racionalidad política autoritaria" (Sozzo en Hathazy 2005, 148).

\section{e) Características Estructurales/institucionales}

La siguiente tabla muestra las características que posee cada una de las policías que se analizarán en esta investigación y que servirán como insumo para comprender el desarrollo de los procesos de reforma que estas instituciones han tenido a lo largo de los años. 
Tabla $\mathrm{N}^{\circ} 1$ : Características de las Policías

\begin{tabular}{|c|c|c|c|}
\hline & Carabineros de Chile & $\begin{array}{c}\text { Policía Nacional de } \\
\text { Ecuador }\end{array}$ & $\begin{array}{c}\text { Policía Nacional de } \\
\text { Colombia }\end{array}$ \\
\hline Ley que las crea & $\begin{array}{c}\text { Constitución Política de la } \\
\text { República de Chile. Ley } \\
\text { Orgánica de Carabineros de } \\
\text { Chile } \mathrm{N}^{\circ} 18.961 .\end{array}$ & $\begin{array}{l}\text { Constitución de la } \\
\text { República del Ecuador. Ley } \\
\text { Orgánica de la Policía } \\
\text { Nacional } N^{\circ} 109 .\end{array}$ & $\begin{array}{l}\text { Constitución de la República } \\
\text { de Colombia. } \\
\text { Ley } 62 \text { de } 1993 \\
\text { Ley Orgánica de la Policía } \\
\text { Nacional de Colombia. }\end{array}$ \\
\hline $\begin{array}{l}\text { Designación del } \\
\text { alto mando }\end{array}$ & $\begin{array}{l}\text { El presidente de la República } \\
\text { elige al General Director, entre } \\
\text { los cinco generales más } \\
\text { antiguos de la institución, por } \\
\text { un periodo de cuatro años. }\end{array}$ & $\begin{array}{c}\text { El presidente de la } \\
\text { República selecciona al } \\
\text { Comandante General, a } \\
\text { pedido del Ministro de } \\
\text { Gobierno, de entre los tres } \\
\text { generales más antiguos en } \\
\text { servicio activo. }\end{array}$ & $\begin{array}{c}\text { El presidente de la República } \\
\text { designa al Director General de } \\
\text { la Policía. Se necesita ser } \\
\text { oficial general de la Policía, } \\
\text { con servicio activo y } \\
\text { especialidad en policía urbana, } \\
\text { rural o judicial. }\end{array}$ \\
\hline Atribuciones & $\begin{array}{l}\text { Prestar auxilio de la fuerza } \\
\text { pública a las autoridades } \\
\text { judiciales si así lo requieren y } \\
\text { colaborar con fiscales del } \\
\text { Ministerio Público en la } \\
\text { investigación del delito. }\end{array}$ & $\begin{array}{l}\text { Prevenir la comisión de } \\
\text { delitos y participar en la } \\
\text { investigación de las } \\
\text { infracciones comunes } \\
\text { utilizando los medios } \\
\text { autorizados por la Ley. } \\
\text { Custodiar a los infractores o } \\
\text { presuntos infractores y } \\
\text { ponerlos a órdenes de las } \\
\text { autoridades competentes } \\
\text { dentro del plazo previsto } \\
\text { por la Ley. Mantener la } \\
\text { seguridad externa de los } \\
\text { centros de rehabilitación } \\
\text { social del país e interna en } \\
\text { casos de emergencia. } \\
\text { Controlar el movimiento } \\
\text { migratorio. }\end{array}$ & $\begin{array}{c}\text { Proteger a todas las personas } \\
\text { residentes, garantizar el } \\
\text { ejercicio de las libertades, } \\
\text { ejercer el rol judicial con } \\
\text { respecto a los delitos y } \\
\text { vigilancia, realizar la función } \\
\text { educativa a través de la } \\
\text { orientación con la comunidad, } \\
\text { trabajar por la solidaridad } \\
\text { entre la policía y ciudadanos, } \\
\text { protección a los recursos } \\
\text { naturales. }\end{array}$ \\
\hline Autoridad Civil & $\begin{array}{l}\text { Ministerio del Interior y } \\
\text { Seguridad Pública. }\end{array}$ & Ministerio de Gobierno. & Ministerio de Defensa. \\
\hline
\end{tabular}




\begin{tabular}{|c|c|c|c|}
\hline Misión & $\begin{array}{c}\text { Encargada del orden público y } \\
\text { la prevención del delito, junto } \\
\text { con otras funciones que le son } \\
\text { inherentes, conforme a los } \\
\text { reglamentos internos. }\end{array}$ & $\begin{array}{c}\text { Atender la seguridad } \\
\text { ciudadana y el orden } \\
\text { público, y proteger el libre } \\
\text { ejercicio de los derechos y } \\
\text { la seguridad de las personas } \\
\text { dentro del territorio } \\
\text { nacional. }\end{array}$ & $\begin{array}{l}\text { Mantener la convivencia como } \\
\text { condición necesaria para el } \\
\text { ejercicio de derechos y } \\
\text { libertades de los habitantes. }\end{array}$ \\
\hline Jerarquización & $\begin{array}{c}\text { Personal de nombramiento } \\
\text { supremo: } \\
\text { General Director de } \\
\text { Carabineros, General Inspector } \\
\text { de Carabineros, General de } \\
\text { Carabineros Oficiales } \\
\text { Superiores, Coronel de } \\
\text { Carabineros Oficiales Jefes, } \\
\text { Teniente Coronel de } \\
\text { Carabineros, Mayor de } \\
\text { Carabineros Oficiales } \\
\text { Subalternos, Capitán de } \\
\text { Carabineros, Teniente de } \\
\text { Carabineros, Subteniente de } \\
\text { Carabineros. } \\
\\
\text { Personal de nombramiento } \\
\text { institucional: } \\
\text { Suboficial Mayor de } \\
\text { Carabineros, Suboficial de } \\
\text { Carabineros, Sargento } 1^{\circ} \text { de } \\
\text { Carabineros, Sargento } 2^{\circ} \text { de } \\
\text { Carabineros, Cabo } 1^{\circ} \text { de } \\
\text { Carabineros, Cabo } 2^{\circ} \text { de } \\
\text { Carabineros, Carabinero. }\end{array}$ & $\begin{array}{c}\text { Rol de Conducción y } \\
\text { mando: } \\
\text { General Superior, General } \\
\text { Inspector, General de } \\
\text { Distrito. } \\
\\
\text { Rol de Coordinación } \\
\text { Operativa: } \\
\text { Coronel de Policía, } \\
\text { Teniente Coronel de } \\
\text { Policía, Mayor de Policía, } \\
\text { Capitán de Policía, Teniente } \\
\text { de Policía, Subteniente de } \\
\text { Policía. } \\
\text { Servidoras o servidores } \\
\text { técnicos operativos. } \\
\text { Rol de Supervisión } \\
\text { Operativa: } \\
\text { Suboficial Mayor, } \\
\text { Suboficial Primero, } \\
\text { Suboficial Segundo. } \\
\text { Segundo, Cabo Primero, } \\
\text { Cabo Segundo, Policía. }\end{array}$ & $\begin{array}{c}\text { Generales: } \\
\text { General Director de la Policía } \\
\text { Nacional, Mayor General, } \\
\text { Brigadier General. } \\
\text { Oficiales Superiores: } \\
\text { Coronel, Teniente Coronel, } \\
\text { Mayor. } \\
\\
\text { Oficiales Subalternos: } \\
\text { Capitán, Teniente, } \\
\text { Subteniente. } \\
\text { Suboficiales: } \\
\text { Sargento Mayor, Sargento } \\
\text { Primero, Sargento } \\
\text { Viceprimero, Sargento } \\
\text { Segundo, Cabo Primero, Cabo } \\
\text { Segundo. }\end{array}$ \\
\hline Capacidad Política & No Deliberante & Deliberante & No Deliberante \\
\hline
\end{tabular}




\begin{tabular}{|c|c|c|c|}
\hline $\begin{array}{l}\text { Mecanismos de } \\
\text { Sanciones }^{2}\end{array}$ & $\begin{array}{l}\text { En el Reglamento } \mathrm{N}^{\circ} 15 \mathrm{se} \\
\text { establecen las características } \\
\text { del sistema de sumario, que es } \\
\text { ejecutado por el superior } \\
\text { jerárquico y tiene dos } \\
\text { instancias de apelación; puede } \\
\text { desembocar en amonestación } \\
\text { verbal, multa, suspensión, } \\
\text { destitución. }\end{array}$ & $\begin{array}{c}\text { La competencia } \\
\text { disciplinaria recae en el } \\
\text { superior jerárquico directo, } \\
\text { quien determinará una } \\
\text { investigación sobre los } \\
\text { hechos. En casos de } \\
\text { extrema gravedad se puede } \\
\text { instaurar una sanción } \\
\text { directa. }\end{array}$ & $\begin{array}{l}\text { Destitución e inhabilidad } \\
\text { general (término de la relación } \\
\text { laboral con la institución e } \\
\text { imposibilidad de ejercer } \\
\text { cargos públicos por un } \\
\text { tiempo), suspensión, multa, } \\
\text { amonestación escrita. }\end{array}$ \\
\hline Fuentes & $\begin{array}{l}\text { Ley Orgánica Carabineros de } \\
\text { Chile (Ley 18.961, 1990). }\end{array}$ & $\begin{array}{l}\text { Ley } 123 \text { de Personal de la } \\
\text { Policía del Ecuador, Código } \\
\text { Orgánico de Entidades de } \\
\text { Seguridad Ciudadana. }\end{array}$ & Ley 62 de 1993. \\
\hline
\end{tabular}

\section{Encuadre Histórico de los intentos de reforma}

\section{Chile: Carabineros de Chile}

El régimen militar en Chile no solo marcó la historia del país, sino también a las policías. El miedo latente a una regresión autoritaria limitó las capacidades de los diferentes actores del escenario político para poder generar transformaciones y cambios sustanciales dentro de las instituciones; de hecho, en palabras del presidente Patricio Aylwin, se buscaría la "justicia en la medida de lo posible", declaración que permeó el tono de la democracia durante los gobiernos de transición,, considerando además el hecho de que los distintos enclaves autoritarios seguían teniendo una fuerte presencia en la democracia de la época. Respecto de estos últimos, Manuel Antonio Garretón los definió como “ciertos elementos del 'régimen anterior' que persisten en 'el régimen democrático"” (Garretón, 1995 en Siavelis, 2009).

Durante la dictadura, Carabineros de Chile formó parte de la Junta Nacional de Gobierno, mientras que la Policía de Investigaciones (actual PDI) fue subordinada a Pinochet y al Ministerio de Defensa (Hathazy, 2016). Al finalizar este periodo, y luego con el paso a la transición a la democracia, el principal peligro que determinó la institución de Carabineros tuvo que ver con una posible devaluación simbólica de su papel de guardianes de la seguridad del Estado; frente a esto, la institución busca realizar cambios en su doctrina, administración, despliegue y relación con la ciudadanía (Hathazy, 2016).

\footnotetext{
${ }^{2}$ Para determinar los mecanismos de disciplina, se hace necesario distinguir entre el crimen — que ocurre cuando un funcionario rompe una ley en particular - y el disciplinamiento - relacionado con la falta de cultura organizacional de la institución en particular-. Ambas categorizaciones se interceptan, pero la disciplina abarca una mayor cantidad de comportamientos.
} 
Carabineros contaba con mayor independencia y autonomía, por lo que los cambios que sufrió fueron el resultado de una pugna entre el poder ejecutivo y la propia institución (Hathazy, 2016). Este aspecto se visualiza en la disputa que existió entre el poder ejecutivo y el Comandante en Jefe de la institución, que permeó en el proceso de reforma de esta por las diferentes solicitudes realizadas por parte del gobierno y que, pese a la negativa de Carabineros, se consolidaron de igual manera, pero conforme a sus propios requerimientos y lineamientos.

La transición a la democracia trajo consigo a nuevos actores políticos y a distintas ideas para la reciente administración del Estado y sus instituciones. Respecto de la seguridad pública, se creó el Consejo de Seguridad Pública, en 1991, y la Dirección General de Seguridad Pública y de Información (DISPI), en 1993. Junto con esto, se realizó un llamado a distintas comunidades, principalmente de académicos, especialistas y profesionales que tenían una nueva visión acerca de cómo debería funcionar la policía, en base a una crítica al dogma de seguridad que se había heredado de la dictadura y proponiendo un enfoque mucho más ligado a lo gerencial. Los nuevos especialistas propusieron una política en la que se excluyó a los militares del orden interno, en la que se planteó como eje central la protección a los ciudadanos y el respeto de sus derechos. Además, se consideró que la supervisión política a la policía debía estar asociada a la eficacia y a la eficiencia en el uso de los recursos públicos destinados a la institución (Hathazy, 2016, p. 606).

Durante la primera década de la democracia, y a la fuerza luego de una pugna política, Carabineros de Chile se autorreforma. El poder ejecutivo y la dirección de Carabineros se vieron enfrentados en 1994, cuando el General Rodolfo Stange fue denunciado por obstrucción a la justicia en el marco de las investigaciones relacionadas con el Caso Degollados. El presidente Frei Ruiz-Tagle solicitó la renuncia de Stange, quien se negó a dejar su puesto; sin embargo, el ejecutivo presionó por medio de reducciones presupuestarias y de otros nombramientos, además de la solicitud de un plan de modernización de la institución (Hathazy, 2009, p. 8).

A mediados de ese mismo año, Carabineros elaboró el Plan de Modernización, centrado fundamentalmente en una "educación profesional, el respeto de la dignidad humana, la eficiencia en la producción de seguridad y la reincorporación de tecnología (Stange Oelckers, 1995); no obstante, el gobierno y sus especialistas consideraron que el plan era insuficiente y el conflicto terminó con el retiro de Stange. Tras la salida de éste, en 1995, fue Fernando Cordero Rusque quien tomó su lugar. A diferencia de Stange, Cordero Rusque promovió un modelo gerencial, en línea con lo que buscaba el proyecto, y posibilitó la elaboración de un Plan Estratégico de Carabineros, que contempló cuatro modernizaciones en recursos humanos, logística, comunicaciones, relaciones públicas y operaciones.

En línea con las modernizaciones, dentro de Carabineros se adoptaron una serie de medidas técnicas en los sectores administrativos, además de la incorporación de medidas en los sectores operativos. De esta forma, en 1998 surgió el Plan Cuadrante de Seguridad Preventiva, destinado a brindar una mayor seguridad, buena convivencia social y mayor confianza entre la institución y la ciudadanía, además de solucionar los problemas que aquejaban a la comunidad. Para lograr estos objetivos, se realizó una división del territorio jurisdiccional de cada comisaría (Oviedo, 2007, p. 75).

En la búsqueda de una mayor cercanía con la población y el accountability se propuso un modelo de acercamiento policía-comunidad y de este modo tratar correctamente las demandas de la ciudadanía, lograr la familiarización entre la institución y los problemas de la comunidad y, como consecuencia, mejorar la confianza en la institución (Hathazy, 2016). En el año 2000 se amplió el Plan Cuadrante a toda la Región Metropolitana y, con posterioridad, se aplicó a toda la nación (Ministerio de Hacienda, 2006). 
A nivel local, el entonces alcalde de Las Condes, Joaquín Lavín, importó el modelo "Tolerancia Cero" desde Estados Unidos. Dicho modelo buscaba prevenir y disminuir el delito otorgando más facultades a la policía municipal; en 1998 intentó ponerlo en marcha en Las Condes, pero los guardias municipales fueron detenidos por Carabineros, quienes argumentaron que este modelo significaba una provisión de seguridad desigual para los municipios más pobres. El gobierno apoyó esta idea y el plan no pudo seguir funcionando (Hathazy, 2016, p. 609). Finalmente, en años posteriores, si bien este plan fue desechado, planes de seguridad ciudadana similares van a ser implementados en diferentes comunas de Chile.

En 2003, gracias a la actividad conjunta entre expertos en seguridad ciudadana y diversas instituciones sectoriales del Estado - Carabineros de Chile, centros de estudios y la Policía de Investigaciones - se elaboró una Política Nacional de Seguridad Ciudadana; esta instancia buscaba la institucionalización e integración de los programas existentes en materia de seguridad y prevención del delito. Además, pretendía mejorar la coordinación interinstitucional, aumentando su efectividad y sentando, de esta manera, las bases para una política de Estado sostenible en el tiempo (Frühling, 2006, p. 3); junto con esto, se estableció el compromiso de enfrentar la violencia familiar como un problema país y la creación de un sistema de información sobre violencia, delito e inseguridad (Oviedo, 2007, p. 76).

La Política Nacional de Seguridad Ciudadana tenía como principal objetivo la reducción de la violencia y la delincuencia, así como también la disminución de la sensación de inseguridad. En cuanto a los objetivos específicos, buscaba recuperar los espacios públicos urbanos, fomentar la participación ciudadana en estrategias preventivas, entre otras. Todo esto en el marco de la instalación de un modelo de policía comunitaria que buscaba una mayor participación de la sociedad en las labores policiales para mejorar, de esta manera, la relación policía-comunidad al hacer parte a esta de la seguridad ciudadana, puesto que son ellos quienes están más familiarizados con los problemas de las comunidades.

En la práctica, y a pesar de todos estos objetivos, la reforma fue una instrumentalización de las comunidades antes que una apertura a la participación ciudadana en la institución. Esto se ratifica si se considera el modelo de policía comunitaria que tiene Chile: según Claudia Labra (2011), los cambios que se realizaron a la institución fueron más bien modernizaciones que no tocaron el entramado institucional. En relación con el control de las policías, Frühling, (2006) señala que una transformación de las instituciones policiales debiese contemplar el que estas sean modernas, eficientes y respetuosas de los derechos humanos. Otro aspecto a destacar es que en el modelo de policía comunitaria existe un feedback o intercambio de información entre la ciudadanía y la entidad policial, elemento que no se da en Chile porque existe dificultad en el acceso a la información: a pesar de la promulgación, años más tarde, de la Ley de Transparencia.

La Estrategia Nacional de Seguridad Pública también se enmarca en los procesos de modernización y en los planes estratégicos de los gobiernos. Durante los años 2006-2010 las metas se asocian a reducción de los hogares victimizados por algún delito, en un $10 \%$, así como la reducción de aquellos delitos de mayor connotación, en un 9\%, además de la realización de un trabajo conjunto con otras instituciones públicas comprometidas con la Estrategia Nacional, en la que se abordaron diversos ámbitos de solución al problema de las violencias, delitos y el temor. Carabineros de Chile vio en esta estrategia una oportunidad de cohesión con la ciudadanía, que se ha perdido a medida que ha transcurrido el tiempo.

A modo general, es posible seguir mencionando diferentes modernizaciones y planes estratégicos en los que la policía chilena tiene un rol participativo importante, pero en lo sustancial no han existido reales reformas a la institución, sino solo planes y modernizaciones 
muy por debajo del intocable modelo institucional. Por esta razón, algunos autores han señalado que Carabineros de Chile no logra encasillarse dentro de un modelo tradicional de policía comunitaria, sino que se han transformado en una especie de "community policing", es decir, una variante del modelo en la que se involucra a la sociedad en una labor más estrecha con la policía, pero sin que se realicen reformas profundas en el funcionamiento institucional (Labra, 2011, p. $57)$.

Con posterioridad a la revuelta social del 18 de octubre del 2019, surgió la necesidad —y también la tarea- de reformar o refundar la institución de Carabineros, gatillada principalmente por las denuncias de violaciones a los derechos humanos en el marco de las protestas ciudadanas por derechos fundamentales y una vida digna. Los casos de violencia policial hacia comunidades específicas — pueblo mapuche, comunidad LGBTIQ+, estudiantes y vendedores ambulantes-, además de los casos de corrupción al interior de la institución — y por parte de los altos mandos institucionales - han generado repudio en la población y han aumentado la necesidad urgente de una reforma policial.

\section{Colombia}

La Policía Nacional Colombiana es una institución que se creó en 1891 y que ha experimentado distintos procesos de cambios, reformas y contrarreformas. Tiene una estructura jerarquizada, de carácter profesional y disciplina militar. En el momento de realizar esta investigación, estas prácticas han sido altamente cuestionadas por la sociedad civil, principalmente como consecuencia de los altos niveles de violencia que existe hacia los ciudadanos, ya sea en las detenciones y en las manifestaciones o en los casos de corrupción y vínculos con el narcotráfico. Aunque estos hechos han ocurrido de forma constante, fue el 23 de febrero de 1993 cuando se pidió una reforma estructural a la policía de carácter urgente, luego de que en un cuartel de policía se encontrara el cuerpo de una niña de 9 años, quien había sido violada y brutalmente asesinada.

En el año 1993, bajo el gobierno de César Gaviria y con la ayuda del Ministro de Defensa — Rafael Pardo_, se decidió llevar a cabo la primera reforma policial. Álvaro Camacho (2000) identifica cuatro factores que estuvieron involucrados en esta crisis: la subordinación de la policía a los intereses privados, legales o no, que tenía como consecuencia que la institución hiciera lo que determinaban las élites locales; la tendencia a la autonomización, que incidía en que muchos de sus miembros se vieran involucrados en actos delictivos; la ineficacia de la policía en la defensa de los ciudadanos $\mathrm{y}$, finalmente, la estructura altamente jerarquizada en los niveles directivos.

Para concretar el proceso de reforma, se crearon dos grandes comisiones consultivas, una compuesta por la policía - interna - y otra conformada por la sociedad civil, gremios, clase política, entre otros actores - externa-. Estas dos comisiones encontraron grandes similitudes, entre las que destacan las necesidades y cambios requeridos por la institución policial y que se materializaron en las debilidades institucionales que identificaron, fundamentalmente como "fallas en la formación policial y ética (no existiendo una conexión entre la preparación académica y la realidad del servicio), fallas en la conducción de unidades, carencia de mandos medios oficiales subalternos y suboficiales, exceso de funciones ante el crimen" (Casas, 2005). 
Considerando estas similitudes, se inició un debate para diseñar nuevos puestos y crear nuevas instituciones que se sumaran a esta reforma. Para quebrar el carácter jerarquizado de la institución se propusieron ideas como facilitar el ascenso de los policías y crear el Instituto para la Seguridad Social y Bienestar, cuyo objetivo era brindar educación, salud, vivienda y entretención a los escalafones más bajos de la institución. Los cambios en el sistema operativo estuvieron orientados a la definición de una policía urbana y rural que fuera capaz de enfrentar la insurgencia armada. Este fue uno de los grandes desafíos que tuvo que enfrentar la policía colombiana, puesto que la ausencia de unidades policiales en el sector rural posibilitó el fortalecimiento de distintas redes de insurgencia.

Para contribuir en el combate al narcotráfico, en el año 1995 se crearon la Dirección de Inteligencia (DIPOL) y la Superintendencia de Vigilancia, que fiscalizaban a las empresas de seguridad privada, puesto que muchas de ellas estaban ligadas al narcotráfico. Ambos organismos existen hasta el día de hoy y son exclusivos de la institución policial.

Como hecho novedoso, se destaca el papel que se le asignó a la sociedad civil al hacerla partícipe de este proceso: se invitó a la mayor cantidad de ciudadanos posibles a participar, pero se enfrentó una dispersión muy amplia de temas, por lo que el proceso se convirtió en algo extremadamente masivo. Aun así, esta propuesta ciudadana fue finalmente archivada y no tuvo efecto alguno en la práctica (Camacho, 2000).

En el año 1995, el país enfrentó una crisis política que afectó a su estabilidad al descubrirse que el presidente Ernesto Samper tenía vínculos con el narcotráfico, derivados de su anterior campaña presidencial. Asimismo, las fuerzas militares se vieron involucradas en una serie de escándalos por su presunta participación en política, mientras que la Policía Nacional, en cambio, tenía un muy buen desempeño en el combate contra los cárteles de droga, lo que le valió el amplio reconocimiento internacional y, de esta manera, un empoderamiento institucional que significó que se dejaran atrás todos los cambios propuestos por las comisiones anteriores y se echara a andar un plan propio de reforma policial (Casas, 2005). De esta manera, la policía presentó su propio diagnóstico, conocido como contrarreforma, muy similar a lo que anteriormente presentaron las comisiones interna y externa. En este informe, se consideraron los altos niveles de corrupción, la poca respuesta institucional a la delincuencia y la falta de conexión entre la policía y las demandas ciudadanas; finalmente, se concluyó que era un buen momento para la realización de cambios profundos (Casas, 2005).

A pesar de todo esto, se cancelaron los planes anteriores que consideraban cambios en materia ciudadana. Se desmontó la Oficina del Comisionado Nacional para la Policía y el Instituto para el Bienestar y Seguridad Social de la Policía — que tenía como objetivo la entrega de beneficios a los policías-, se modificó la estructura orgánica de la institución eliminando la figura de los Comandos Municipales y las Subdirecciones de Policía Rural, de Policía Urbana y de Participación Ciudadana. El Consejo Nacional de Policía nunca se convocó para desarrollar las funciones que en materia de formulación de políticas y seguimiento de resultados le había asignado la ley (Casas, 2005).

En relación con la militarización, se planteó la idea de desligarse de ella; sin embargo, la militarización ha estado arraigada en la institución desde el año 1953, cuando el gobierno central decidió entregar atribuciones militares a la policía para combatir la insurgencia (Cruz-Rodríguez, 2017). No obstante, la tendencia a la desmilitarización se vio afectada por el Programa de Transformación Cultural, un proyecto interno de la Policía Nacional que implementó la propia policía entre los años 1995 y 1998 que, por las dinámicas propias de la guerra, llevaron a acentuar 
su carácter militar, como sucedió con la Política de Seguridad Democrática (Cruz-Rodríguez, 2017).

Una nueva crisis social se presentó en 2003, cuando se incautaron tres toneladas de cocaína a un grupo de policías. Las críticas reiteradas hicieron que el gobierno llamara a una comisión de expertos para reformar. La "Misión", como fue denominada, realizaría propuestas a puertas cerradas, muy distinto a lo que se quiso hacer en la reforma de 1993; esto generó una resistencia por parte de la policía, principalmente porque el grupo de expertos propuso cambios que no encajaron con la Política de Seguridad Democrática, un programa de Álvaro Uribe destinado al combate de la insurgencia. Los cambios propuestos en el año 2003 fueron:

Analizar y evaluar la situación actual de la policía y establecer un plan de acción para prevenir y corregir conductas que lesionen la ética en la institución [...] analizar y evaluar los mecanismos y las prácticas internas de la Policía Nacional encaminadas a prevenir la corrupción y mantener un canal de información de la ciudadanía [...] formular recomendaciones para asegurar las mejores prácticas de control interno $[\ldots]$ de control externo [...] analizar y evaluar los mecanismos que utiliza la Oficina del Comisionado Nacional para la Policía. (Casas, 2005, p. 46)

A diferencia de la reforma de 1993, esta vez la comisión de expertos realizó un diagnóstico de la administración de recursos y personal, lo que significó un llamado de atención a las prácticas poco transparentes de la institución. Con estas propuestas, el gobierno estudió los cambios para hacerlos efectivos, pero esto no logró concretarse. La Policía Nacional Colombiana se intentó reformar dos veces, pero esto fue insuficiente e incluso en el 2003 se intensificó su autonomía. Luego de este intento de reforma, el tema se dio por concluido y la institución policial guardó silencio ante los cambios.

En 2014 salió a la luz pública un escándalo en el que se denunció una red de prostitución masculina en la que los cadetes ofrecían sus servicios sexuales a distintos miembros del poder legislativo: cargos del alto mando de la policía también estaban involucrados. Como consecuencia de estos hechos, el General Rodolfo Palominos presentó su renuncia, porque los videos que se difundieron por este hecho también lo involucraban a él. Cuatro años más tarde, en noviembre de 2018, la Procuraduría General absolvió a Palomino de una investigación disciplinaria y en la fiscalía se archivaron dos procesos que se relacionaban con el constreñimiento a la prostitución (El Tiempo, 2019).

En 2019, específicamente a partir del 21 de noviembre de ese año, Colombia vivió un paro nacional consecutivo en distintas ciudades del país. Distintos grupos de la ciudadanía se alzaron en las protestas en las que se denunció la desigualdad en temas prioritarios como, por ejemplo, la salud, la educación, previsiones sociales, entre otros. Estas manifestaciones no estuvieron exentas de diversos hechos de violencia policial (CIPER Chile, 2019).

En marzo del año 2020 comenzaron a aparecer los primeros casos de Covid-19, en el marco de la pandemia por el Coronavirus. Ante esta situación, el gobierno decidió, a modo preventivo, instalar medidas de confinamiento para que los ciudadanos se quedaran en sus hogares, por esta razón las protestas comenzaron a declinar. El poder ejecutivo impuso un toque de queda y, en este contexto, ocurrió un grave hecho que sacudió a la opinión pública: la muerte de Javier Ordoñez. El ciudadano se encontraba en la calle en el horario de toque de queda, cuando fue detenido por un grupo policial que procedió a reducirlo y a efectuar descargas eléctricas en su cuerpo; mientras esto ocurría, un grupo de personas que presenciaban el hecho filmaron un video 
en el que le piden a la policía soltar al hombre quien, posteriormente, es llevado a una comisaría en la que se constató la gravedad de sus heridas. En el recinto policial, Ordoñez pierde la vida antes de ser trasladado a un servicio de urgencias, lo que desencadenó diversas protestas ciudadanas que tuvieron consecuencias en heridos (209 civiles y 194 policías) y 10 muertos. (CNN, 2020). En este contexto, la discusión sobre una reforma vuelve a surgir en el ámbito político, académico, en la sociedad civil y en los diferentes medios de comunicación.

\section{Ecuador}

La Policía Nacional del Ecuador es heredera de un complejo y extenso proceso histórico. Sin embargo, son dos los eventos que marcan el desarrollo de la actual institucionalidad. El primero de ellos corresponde a la promulgación de la Ley Orgánica de 1998, que otorgó a la policía una alta autonomía administrativa y financiera con muy poca supervisión de los poderes civiles (Pontón, 2014). La segunda coyuntura histórica corresponde a la instalación de la Doctrina del Enemigo Interno por parte de gobiernos cívico-militares, aspecto que direccionó el crecimiento institucional hacia una mayor eficiencia en el despliegue sistemático de la represión estatal, recurriendo a la tortura y el asesinato extrajudicial (Jarrin, 1991 \& Comisión de la Verdad Ecuador, 2010).

En este contexto, la actual iteración de la Policía Nacional comienza a forjarse luego de un período de alta turbulencia política en el que se sucedieron tres derrocamientos en los años 1997, 2000 y 2005. El último, ocurrido tras la Rebelión de los Forajidos, culminaría con la elección de Rafael Correa como presidente, por medio de una plataforma política que unía a diversos movimientos sociales, cuya propuesta fuerte fue la promulgación de una nueva Constitución. Ésta amplió las capacidades del presidente en materia policial, pudiendo reformar a las policías mediante decreto. Además, logró que la justicia policial pasara a manos del poder judicial ecuatoriano a través de tribunales especializados en la materia y consiguió la creación de un Consejo Sectorial Ciudadano de Seguridad Ciudadana, una instancia de participación ciudadana formal en los procesos internos policiales (Constitución de la República del Ecuador, 2008).

Paralelamente, durante ese mismo año se creó la Comisión de Modernización de la Policía Nacional, cuyo objetivo fue aumentar la eficiencia y eficacia mediante la redacción de un Plan Nacional de Seguridad Ciudadana. Este otorgó un aumento presupuestario de 320 millones de dólares, de los cuales 280 fueron para la policía y 40 para justicia y rehabilitación social. Además de esto, se creó la Unidad de Ejecución del Plan de Seguridad Ciudadana como entidad adscrita al Ministerio de Gobierno para la ejecución de proyectos previamente presentados por la Policía Nacional (Pontón, 2018).

En 2009 se aprobó una nueva Ley de Seguridad Pública y del Estado, que creó una instancia de autoridad civil sobre las policías; el Consejo de Seguridad Pública y del Estado. Adicional a esto, en el artículo 35 se estableció que, una vez declarado el estado de excepción y a petición presidencial, las Fuerzas Armadas podrían apoyar a la Policía Nacional en el mantenimiento del orden público hasta que este haya sido restablecido.

El 30 de junio del 2010, el presidente promulgó el decreto presidencial $\mathrm{N}^{\circ} 410$, que dividió al Ministerio de Gobierno en tres partes: un Ministerio del Interior que mantuvo la autoridad civil sobre las policías, el Ministerio de Justicia, Derechos Humanos y Cultos y, 
finalmente, un Ministerio de Coordinación de la Política y Gobiernos Autónomos Descentralizados.

En el mismo año, y a raíz de la aprobación de la Ley de Servicio Público, se generaron varias protestas por parte de efectivos del ejército y la Policía Nacional. En un intento por disminuir las tensiones, el presidente se acercó personalmente a un cuartel para explicar las ventajas de las nuevas medidas adoptadas y notificar su decisión de continuar con ellas. Sin embargo, al momento de su llegada, comenzaron una serie de manifestaciones y agresiones que culminaron con la retención forzada del mandatario; por esta razón, se dispuso la entrada de fuerzas especiales de la policía y militares para rescatar al presidente del hospital policial, lo que derivó en un cruce abierto de disparos que causaron la muerte de 10 personas (entre policías, militares y civiles) y dejaron varios cientos de heridos (El Comercio, 2011). Frente a estos hechos, se inició un proceso de reforma a la Policía Nacional que tuvo como principal medida la creación del Servicio de Protección Presidencial a través del Decreto Ejecutivo No 418 del 2010, quitándole esta capacidad a la Policía Nacional.

En el 2011 se lanzó el decreto presidencial $N^{\circ}$ 632, a través del cual se puso fin a la autonomía legal de la Policía Nacional, instaurada en la Ley Orgánica de 1998. Además, se presentó el nuevo Código Orgánico de Entidades de Seguridad a la Asamblea Nacional, que buscaba crear dos nuevos cuerpos policiales: el Cuerpo Civil de Investigaciones e Infracciones Penales, un cuerpo paralelo de investigaciones de carácter civil dependiente del Ministerio del Interior y un Servicio de Protección Pública, dependiente directamente de la Presidencia.

Otro hito importante fue la Consulta Popular del 11 mayo del 2011; en esta se plantearon reformas constitucionales para limitar la caducidad de la prisión preventiva, así como el uso de medidas sustitutivas a la privación de la libertad. De acuerdo con datos entregados por el Consejo Nacional Electoral, el resultado fue positivo para la campaña del Sí, postura defendida por el gobierno, logrando 47\% del total de los votos emitidos (Consejo Nacional Electoral, 2017).

El año 2014 se aprobó la Ley de Seguridad Pública y del Estado, luego de tres años de debate en la Asamblea Nacional, que permitió que las Fuerzas Armadas tuvieran una competencia directa en el manejo de la seguridad interna. Esto dotó al gobierno de la capacidad de disponer, con mediación de un Estado de excepción, del recurso militar para labores de seguridad ciudadana e interna. A su vez, también entró en vigor el acuerdo ministerial $\mathrm{N}^{\circ} 179$, que permite normar el uso progresivo, racional y diferenciado de la fuerza por parte de los miembros de las fuerzas armadas al establecer un sistema de cinco niveles para clasificar la violencia en caso de marchas, donde a partir del tercer nivel se podía convocar a las fuerzas armadas para el control del orden, siempre y cuando, existiera un estado de excepción y se realizara en complementariedad con la policía.

La promulgación de la ley de Fortalecimiento a los Regímenes Especiales de Seguridad Social de las Fuerzas Armadas y de la Policía Nacional en el 2016, que eran parte de un paquete de reformas provocó nuevamente tensiones entre uniformados y el poder ejecutivo. Entre las reformas que se aprobaron estaba la nueva integración de los consejos directivos del Instituto de Seguridad Social de las Fuerzas Armadas y del Instituto de Seguridad Social de la Policía Nacional, en que los directores de ambas instituciones serían nominados en una terna por el Gobierno, a través de los Ministerios de Defensa y del Interior.

El 21 de junio de 2017 se publicó el Código Orgánico de las Entidades de Seguridad, para regular el funcionamiento institucional y administrativo-disciplinario del personal de las entidades de orden público, lo que incluía a la Policía Nacional, el Sistema Especializado Integral de Investigación, Medicina Legal y Ciencias Forenses. En el tercer libro de este Código, se creó 
el Servicio de Protección Pública, como una entidad de carácter civil, especializada, profesional, técnica y jerarquizada adscrita al ministerio del Interior con la posibilidad de usar medios disuasivos y coercitivos, de conformidad con la ley.

Esta medida causó gran controversia y se presentaron al menos dos proyectos a la Asamblea Nacional para derogar el título III menos de un mes después de su promulgación. Sin embargo, no sería hasta el 6 de junio del 2020 que se podría derogar, mediante reforma, el libro III del Código Orgánico de las Entidades de Seguridad Ciudadana y Orden Público.

En el gobierno de Lenín Moreno se reinstituyó el Ministerio de Gobierno a través del Decreto Ejecutivo $\mathrm{N}^{\circ} 718$, reuniendo al ministerio de del Interior, Secretaría Nacional de Gestión Política y al ministerio de Justicia, Derechos Humanos y Cultos y se creó la Secretaría de Derechos Humanos.

En octubre del año 2019, luego del anuncio del gobierno de un paquete de reformas económicas para liberalizar la economía ecuatoriana, varios sectores de la sociedad comenzaron a organizar movilizaciones masivas. Frente a esto, se dispuso la intervención en todo el territorio nacional de las Fuerzas Armadas y la Policía Nacional para mantener el orden y prevenir acontecimientos de violencia, lo que generó enfrentamientos entre ambas partes.

Ese mismo año se reformó el Código Orgánico Integral Penal, donde se establecieron cinco niveles de uso progresivo de la fuerza para las policías y el cuerpo penitenciario y a partir del tercer nivel — resistencia agresiva agravada - se podía hacer uso de armas letales, y el patrocinio legal del Estado a todos los funcionarios por acciones realizadas en el ejercicio de sus funciones. Esta reforma fue fuertemente criticada por organizaciones de derechos humanos ecuatorianas, pues las justificaciones tales como legítima defensa propia y de terceros o el cumplimiento de orden legítima de autoridad estaban escasamente definidos en la ley (Redacción el Universo, 2020).

El 3 de octubre de 2019 comenzaron una serie de protestas contra el gobierno de Lenín Moreno, que fue respondida con un excesivo uso de la fuerza y generó graves violaciones a los derechos humanos (Human Rights Watch, 2020). De acuerdo con el informe de la Defensoría del Pueblo, se recogieron 519 testimonios, de los cuales 249 correspondían a vulneraciones de derechos humanos perpetradas por agentes estatales: 189 habrían sido cometidas por personal de la Policía Nacional (Defensoría del Pueblo de Ecuador, 2019) Estas situaciones dieron paso a exigencias por parte de la ciudadanía organizada y diversos organismos de derechos humanos nacionales e internacionales por mejorar el sistema de accountability en Ecuador y reformar las policías.

En base a los hechos de violencia descritos anteriormente, el 29 de mayo del 2020 se integró una nueva reforma al Acuerdo Ministerial 179 del Ministerio de Defensa, que estableció que los militares podían usar la fuerza de forma progresiva en protestas o en casos de resistencia social. Sin embargo, el 17 de agosto de ese mismo año, la Corte Constitucional suspendió temporalmente la vigencia de dicho acuerdo en base a que el artículo 158 de la Constitución establecía como función única defender la soberanía y la integridad territorial (García, 2020), generando una fuerte controversia al interior de los poderes del Estado que, hasta el momento de redacción, no ha sido completamente resuelta. 


\section{El debate sobre las reformas}

\section{Carabineros de Chile}

En Chile, el debate sobre una posible reforma policial no se materializó sino hasta las denuncias por las violaciones sistemáticas a los derechos humanos ejecutadas, en el marco del estallido social de octubre de 2019, por parte del cuerpo policial.

Carabineros de Chile acarreaba consigo una serie de irregularidades y casos de corrupción al interior de la institución comprobados, como el "Paco Gate", 3 además de la falta de sanción ante delitos cometidos por los efectivos policiales -sobre todo aquellos ocurridos en el marco de la revuelta social (CIPER, 2020)-, entre otras malas prácticas que no habían reunido la fuerza suficiente para que la sociedad chilena exigiera una reforma policial.

A través de las redes sociales, en manifestaciones pacíficas y en distintos medios de comunicación, un gran sector de la sociedad —académicos, políticos, estudiantes y otros actores de la sociedad civil - expusieron la urgencia de una reforma policial como respuesta a los crímenes cometidos por las fuerzas policiales y la mala gestión de Carabineros de Chile, en general. Según cifras del Ministerio Público, 5.558 personas fueron víctimas de violaciones a los derechos humanos cometidas por agentes del Estado en el contexto del estallido social, 31 personas fallecieron, dos de ellas mientras se encontraban custodiadas por Carabineros. Del total de víctimas, 4.170 sindican a Carabineros de Chile como responsables directos (El Mostrador, 2020).

Como respuesta, el gobierno de Sebastián Piñera convocó a una comisión redactora de una propuesta de reforma, el Consejo de Reforma a Carabineros. Esta comisión estuvo constituida por distintos actores entre los que destacaron Jorge Burgos Varela, ex Ministro del Interior y Seguridad Pública; Jorge Correa Sutil, ex Secretario de la Comisión Rettig; María Luisa Sepúlveda Edwards, Presidenta del Museo de la Memoria y los Derechos Humanos y Marta Salcedo de la Fuente, Coronel en retiro de Carabineros de Chile. El escrito que emana de esta comisión fue publicado en enero de $2020 .^{4}$

La iniciativa de reforma propuesta por el consejo fue duramente criticada, porque se centró en la entrega de mayores facultades a Carabineros, además de dotarlos de una mayor capacidad técnica y elementos que facilitaran sus tareas. Se trató de una mejora en términos de modernización, que contempló procesos, incentivos y tecnologías a la nueva institución para realizar una prestación efectiva de sus servicios que se correspondiera con el uso responsable de los recursos públicos, pero orientada fundamentalmente al combate del crimen y al aumento de la mano dura, brindando a los efectivos policiales mejoras para cumplir esta labor. La reforma no consideró la desmilitarización de la institución, así como tampoco un cambio de la cultura al interior de esta. Esto va de la línea con lo que se menciona en apartados anteriores con respecto a la resistencia que posee la institución a ser cambiada e incluso estudiada pues, si se analiza con detención, las propuestas de esta reforma en ningún momento apuntan a cambiar el eje central de la institución, ni siquiera se menciona alguna modificación a su estructura orgánica.

\footnotetext{
${ }^{3}$ Caso de corrupción por malversación de fondos públicos por parte de Carabineros de Chile. Véase más información en: https://www.meganoticias.cl/nacional/254745-fraude-carabineros-malversacion-pacogate-bruno-villaloboscronologia-hitos-felipe-avila-flavio-echeverria-eduardo-gordon-fiscal-eugenio-campos.html

${ }^{4}$ Para más información, véase "Consejo de reforma a Carabineros".
} 
Entre las propuestas destaca la creación de un nuevo ministerio que se dedique únicamente a la seguridad pública —el Ministerio de Seguridad Pública - y que se organice como un ente rector del poder ejecutivo, destinado a la dirección estratégica y a la supervigilancia de la seguridad, en cuanto a la conducción, al control y a la evaluación de las instituciones policiales. Además, se consideraron otras aristas, como la mejora de la accountability, un sistema de rendición de cuentas en el que la sociedad pudiese inmiscuirse más en los temas relacionados con la institución (Consejo Asesor Reforma a Carabineros, 2020).

En cuanto a derechos humanos y al actuar de Carabineros en diferentes contextos de manifestaciones ciudadanas, se aludió a una mejora en la relación entre efectivos policiales y manifestantes, recalcando el compromiso a actuar bajo los estándares establecidos, pero no se vieron otras iniciativas relacionadas a este punto. De esto se puede inferir una intención de reforma que se enmarca en ciertas temáticas, sin que exista una propuesta estructural de cambio a la institución, sino que se trata de modernizaciones muy similares a las que ya ha experimentado a lo largo de los años, orientadas principalmente al combate del crimen y del delito y a la prevención de este, algo que también se ha reforzado en ambos gobiernos de Piñera, reiterando la tónica del discurso "anti-delincuencia y mano dura".

El académico Mauricio Duce ha argumentado que lo negativo en esta materia tiene que ver con que el presidente confunde la reforma necesaria a Carabineros con otras reformas que se relacionan con problemas de seguridad, como por ejemplo la reforma a la Ley Antiterrorista o la reforma a la Ley de Inteligencia. "Es preocupante que el presidente vuelva a insistir que la reforma policial se satisface con proyectos de modernización y de especialización preferente que están en el Parlamento" (CNN Chile, 2020).

La propuesta de reforma a Carabineros estuvo en pausa por el impacto de la pandemia del Coronavirus en el panorama político, pero el debate de la reforma fue un tema que siguió generando controversia entre los distintos sectores; mientras algunos califican esta reforma como necesaria para el control del actuar policial y la limitación de atribuciones del mismo, existe otro sector que alaba la labor de Carabineros y manifiesta que una reforma policial debiese enfocarse en el combate del crimen y el establecimiento de mano dura a la delincuencia, incluyendo en este último grupo a los manifestantes. Esta discursiva se torna importante de analizar, pues será un eje articulador de parte de las propuestas, con la tónica de "mano dura" y de defensa contra "el enemigo interno", que apunta directamente a aumentar las libertades en torno al uso de la fuerza y los recursos para combatir esta problemática, más no de realizar cambios sustanciales al interior de la institución, pero por otro lado, están aquellas que buscan darle otro matiz, argumentando que es este mismo discurso el que ha provocado que la institución venga decayendo con los años.

Entre quienes defienden el actuar policial se encuentra el político José Antonio Kast, presidente del Partido Republicano, quien ha señalado a la prensa: "yo estoy ahí; los defiendo con fuerza y convicción" (Teletrece, 2020), luego de que funcionario de Carabineros lanzara a un adolescente de 16 años desde el puente Pío Nono, en el contexto de una manifestación en octubre del mismo año (INFOBAE, 2020). Kast ha sido crítico respecto de la reforma de Carabineros, puesto que la considera innecesaria, ya que, según su punto de vista, el problema no radicaría en la institución, sino en el Ministerio Público. Inclusive, el ahora candidato presidencial ha señalado en sus redes sociales que "no se necesita una reforma a Carabineros. Se necesita mano firme contra el vandalismo, el narcotráfico, el terrorismo y la delincuencia, ¡basta de cobardía!" (Kast, 2020).

En relación con el gobierno, este respaldó la labor de Carabineros. El presidente Piñera expresó su profundo apoyo a la institución porque, de acuerdo con sus palabras, "son la primera 
línea que nos defiende de males como la delincuencia" (ADN, 2020); sin embargo, también emplazó al congreso a poner en tramitación y acuerdo al proyecto de ley que reforma y moderniza a la institución, enfatizando la idea de la mano dura y de una criminalización de la protesta en sus discursos, situación que se condice con los dichos anteriormente mencionados de figuras políticas.

Incluso, sosteniendo el argumento de no modificación de la institución y la resistencia que esta debe tener a los inminentes cambios, la Asociación Gremial de Oficiales de Armada en retiro, manifestó su rechazo a la reforma a Carabineros de Chile mediante un comunicado, puesto que consideran que el hecho de "democratizar a su personal" solamente proporcionará una "policía civil cuyo propósito parece acercarse peligrosamente a modelos de organizaciones policiales dependientes del poder político existentes en otras latitudes" (ASOFAR A.G, 2020).

La discusión sobre la reforma vuelve a ser tema luego de que se registraron dos hechos de violencia policial importantes; uno en Talcahuano, en noviembre del 2020, cuando un operativo policial en dependencias del Servicio Nacional de Menores (Sename) Carlos Macera terminó con dos jóvenes heridos a bala por parte de Carabineros, luego de que un funcionario disparara su arma de servicio para controlar a los NNA ${ }^{5}$ del recinto. (La Tercera, 2020).

Estas acciones causaron un amplio rechazo del actuar institucional de Carabineros, por lo que se exigió la salida del General Director de Carabineros, Mario Rozas, quien renunció a su cargo a la mañana siguiente siendo reemplazado por el General Ricardo Yáñez. A su salida, el presidente señaló ante los medios su gratitud ante la labor realizada por Rozas en la institución, sobre todo en tiempos difíciles y con tanta violencia (Diario UChile, 2020).

La diputada Maya Fernández emplazó al Ministerio del Interior a destituir a la autoridad de Carabineros (Meganoticias, 2020) y el diputado Tucapel Jiménez declaró que "lo que ocurre al interior de Carabineros ya no da para más", por lo que "es urgente la designación de un interventor civil para Carabineros de Chile, a fin de colaborar desde una perspectiva alejada de los procesos internos de la institución, en la organización y mejoramiento de nuestra policía uniformada", aludiendo que la institución no "puede seguir mandándose sola", como señala el jefe de la bancada del Partido por la Democracia (PPD), Raúl Soto, al ser consultado por los mismos hechos (CNN Chile, 2020).

El segundo hecho data del 5 de febrero de 2021, en Panguipulli, donde un joven malabarista murió baleado por un efectivo de Carabineros de Chile. El incidente habría ocurrido durante un control de identidad en el que se generó un enfrentamiento con dos carabineros; el joven portaba sables de utilería con los que habría amenazado a los efectivos policiales, quienes apuntaron con sus armas de servicio y uno de los funcionarios dispara en reiteradas ocasiones al cuerpo del joven, quien falleció en el lugar producto de las heridas (Teletrece, 2021).

Desde el gobierno, la ministra Karla Rubilar planteó la urgencia de una refundación de la policía, un término acuñado por la oposición ante la negativa al proyecto de reforma propuesto por el gobierno a raíz de los últimos hechos de violencia policial. Rubilar señaló: "es mi opinión personal, creo que hay que refundar las policías de orden público, creo que hay que darle otro cariz, otro leitmotiv, una capacitación diferente, herramientas acordes al siglo XXI", agregando también que era menester una refundación en materias de orden público, con una policía más especializada y con una capacitación en derechos humanos, entre otras herramientas (El Mostrador, 2021). Este comentario no prosperó en su bancada política.

${ }^{5}$ Niños, niñas y adolescentes. 
Desde la oposición, los partidos del sector señalaron la urgencia de la refundación a Carabineros, ante la necesidad de una nueva policía que, en palabras del presidente del Partido por la Democracia, Heraldo Muñoz, "cumpla con los estándares internacionales mínimos de una policía en democracia". Desde el Partido Socialista enfatizaron también en que se hace necesaria "una reestructuración de Carabineros con énfasis en su formación en derechos humanos y con mecanismos de control internos y externos que velen por un actuar enmarcado siempre dentro del Estado de Derecho" (Emol, 2021).

\section{Policía Nacional de Colombia}

Desde el año 1993, el poder ejecutivo y la Policía Nacional han guiado los procesos de reformas policiales, que, a través de los años, se han manifestado en la creación de instituciones y nuevas leyes. Sin embargo, en la actualidad, la Policía Nacional vive una importante crisis institucional, que ha manifestado la necesidad de una reforma estructural urgente. Los hechos de violencia policial, ocurridos en el marco de un paro nacional convocado por sindicatos, estudiantes y movimientos sociales en noviembre del 2019, tuvieron como consecuencia una lamentable cifra de víctimas y heridos por las fuerzas policiales. Por esta razón, las manifestaciones comenzaron a ser sucesivas y Colombia comenzó a vivir un estallido social. La respuesta de las autoridades fue condenar los hechos de violencia, vandalismo y delincuencia, mediante un toque de queda y mayores sanciones para los destrozos, construyendo así un "enemigo interno", sin embargo, el gobierno no puso atención a las innumerables violaciones a los derechos humanos que estaba sufriendo la ciudadanía en las manifestaciones por parte de efectivos de la Policía Nacional.

A comienzos de marzo el panorama en Colombia cambió con la llegada de la pandemia del Coronavirus, lo que trajo consigo la aplicación de cuarentenas y, por consiguiente, el término de gran parte de las manifestaciones. No obstante, el escenario se complejiza cuando, el 8 de septiembre de 2020, Javier Ordoñez fue detenido por la policía y resultó muerto. Tal como se mencionó anteriormente en este trabajo, el hecho generó un gran impacto en la ciudadanía, provocando una ola de manifestaciones y un nuevo debate de reforma policial en la opinión pública.

La respuesta del presidente Iván Duque fue buscar inmediatamente a los responsables del asesinato de Ordoñez. Asimismo, se acentuó la imagen pública de la alcaldesa de Bogotá Claudia López, del partido Alianza Verde, un personaje político que apuntaba a la reforma de las policías de manera inmediata. El rol comunicacional de esta última ha sido muy importante, ya que forma parte de la oposición a Iván Duque en el aspecto político y, además, critica a este último por no empatizar con las víctimas del abuso policial. Su puesto político es importante, ya que "la Constitución establece que los alcaldes son la primera autoridad de policía en los municipios y los gobernadores en los departamentos" (Constitución Política de Colombia, 1991). Por supuesto, las relaciones entre los alcaldes y los comandantes de la policía en cada ciudad varían, pero en el caso de Colombia, en Bogotá existe una mayor connotación a nivel país, debido a su centralización.

El caso de Javier Ordoñez remeció el escenario político: en el Congreso se propusieron algunas iniciativas que quisieron terminar con el uso de armas letales, reglamentar el uso de las fuerzas, imponer cursos de derechos humanos y realizar reformas constitucionales. Inti Asprilla, 
representante en la Cámara del Partido Alianza Verde, envió un proyecto que buscaba cambiar el Código de Policía, limitar el uso de armas letales y que los policías tuvieran que tener, de forma obligatoria, una formación en derechos humanos. También el expresidente de la Cámara Carlos Chacón, del Partido Liberal, propuso capacitar a los agentes de la policía y claridad de los mecanismos de la institución hacia la ciudadanía (Semana, 2020).

El debate se centró también en el tipo de justicia que debiera aplicarse en el caso de una investigación penal. El 23 de noviembre del 2019, el ciudadano Dilan Cruz fue impactado por una bala en medio de las protestas en el país: dos días después perdió la vida. Este caso se procesó en la justicia militar (El Tiempo, 2019): "En ese sentido, si se logra convertir a la policía en una entidad cívica, se abriría la posibilidad de una reforma constitucional para que su juez natural, en caso de alguna investigación penal, sea la jurisdicción ordinaria y no la castrense como sucede hoy en día" (Semana, 2020).

Mientras que algunos sectores políticos optaron por una reestructuración de la institución policial para evitar estos hechos de violencia, hay otros que argumentan que los hechos de abuso policial son aislados (RCN, 2020). En el caso de los parlamentarios del partido Centro Democrático, estos advierten que los errores cometidos por los uniformados no son en nombre de la institución. La senadora María del Rosario Guerra afirma: "El vandalismo le conviene a los criminales, entonces no podemos generalizar e incentivar el vandalismo, sino por el contrario llamar a que se sancione a los dos responsables de la Policía y el resto que sigan siendo respetuosos de la Constitución y de la ley y sigan dando esa garantía de seguridad" (RCN, 2020).

Según ella, hay algunos líderes "que incitan al odio, a la destrucción, a que se ataque a la Fuerza Pública de los colombianos, que ha sido, entre otras, la que ha defendido a los pueblos de Colombia". Por esta misma línea de pensamiento, el representante de la Cámara Uribista Gabriel Vallejos ha señalado que "no vamos a permitir que mediante un discurso hipócrita y de doble moral desmantelen las instituciones de los colombianos. La Policía Nacional es una institución querida por todos los colombianos" (El Tiempo, 2020).

Otra propuesta que también se encuentra en debate es el cambio ministerial que tutela a la Policía Nacional, desde el Ministerio de Defensa al Ministerio del Interior. A nombre del gobierno, el viceministro Daniel Palacios declaró que la propuesta de remover la policía del ministerio no era algo que estuviera conversado.

El martes 22 de diciembre de 2020 después de dos años de permanencia, Oscar Atehortúa dejaba sus funciones como Director General de la Policía Nacional. El presidente Iván Duque agradeció sus labores entregadas a la institución, destacando la buena evaluación en la lucha contra el vandalismo y el narcotráfico; asimismo, señaló que las razones de su retiro eran confidenciales. A su puesto llegó Jorge Luis Vargas, general de larga trayectoria en materia de inteligencia que tuvo un rol como director de la Dirección de Inteligencia de la Policía (DIPOL), en la que se dieron enfrentamientos con la FARC y poderosas redes de narcotráfico. Otros funcionarios de alto mando también se retiraron, entre ellos Gustavo Moreno, por razones de antigüedad; este último fue protagonista de dichos claves luego de las violaciones a los derechos humanos, diciendo que estos hechos eran aislados y no tenían que ver con la política institucional del país.

El gobierno de Iván Duque recibió críticas de organizaciones que acusaron al gobierno central y la Policía Nacional, en diciembre del 2020: "El colectivo DH Colombia radicará una denuncia en contra el ministro Carlos Holmes Trujillo (Centro Democrático) y otros mandos policiales solicitando investigar la responsabilidad que estos pudieron tener en los hechos de 
abuso policial que se presentaron durante las protestas del 9 y 10 de septiembre" (El Espectador, 2020).

Esta denuncia no se pudo efectuar porque el ministro de defensa falleció de Covid-19 el 26 de enero del 2021, lo que significó un duro golpe para su partido político, ya que sirvió por alrededor de veinte años al gobierno central y, además, se perfilaba como futuro candidato presidencial. En su puesto se designó a Diego Molano, que en sus primeras declaraciones manifestó su preocupación por la delincuencia y la futura lucha con la narco-criminalidad y la seguridad de los ciudadanos en Colombia.

En la conferencia internacional — "Uso excesivo de las fuerzas en Colombia y Chile"-, diferentes académicos entendidos en la materia de ambos países contaron experiencias sobre el uso de la fuerza policial en las marchas y protestas ciudadanas, explicando sus consecuencias, el contexto político y una posible vía de reforma. En el caso colombiano, el politólogo Pedro Piedrahita (2020), analizó el discurso político que normalmente se ha emitido desde el gobierno y de los sectores más conservadores de la sociedad, en donde se transmite una especie de dicotomía en la que la sociedad en su conjunto se ve en la obligación de optar por la seguridad o la violencia. En este caso, si se opta por la seguridad, entonces se justifican el uso de la fuerza y las facultades de la policía; por el caso contrario, si se opta por la violencia, entonces la ciudadanía tendrá que asumir el desorden y vandalismo en las calles. El gobierno de Iván Duque ha tenido la constante de optar por el factor represivo, y criminalizar la protesta, en donde se hacen mayores las atribuciones de la policía. La constante mano dura de los sectores pro -orden se ha visto sin resultados, ya que la represión no contribuye a la protección de los derechos humanos de la sociedad civil, y esta dicotomía resulta sin sentido. (Piedrahita, 2020).

Lucia Dammert en su investigación: "El lado oscuro de las dos policías ejemplares de Latinoamérica" alerta sobre los últimos acontecimientos relacionados con la violencia policial que no han hecho más que sumarse a las distintas irregularidades que la institución estaba cometiendo, en ese sentido el sector político no puede mirar hacia un costado y sustentar el discurso de las manzanas podridas o casos aislados cuando un funcionario recurre a la violencia con un ciudadano: si esta situación continúa, es muy probable la desestabilización de la relación policía/comunidad y se produzca el establecimiento de una poca legitimidad de la policía (Dammert L., 2020).

\section{Policía Nacional de Ecuador}

En Ecuador, el debate sobre una nueva reforma policial tuvo dos momentos álgidos, el primero surge en el contexto de la llamada "Rebelión de los Forajidos" en abril del 2005, en donde distintos grupos sociales se alzaron en contra del gobierno de Lucio Gutiérrez, enfrentando a los efectivos policiales, logrando la destitución de este último. Es en estos enfrentamientos que se registraron serios atentados contra los derechos humanos lo que llevó al gobierno de Correa a tener una retórica y un programa de gobierno que buscaba regular a las policías y limitar sus atribuciones.

Un segundo momento surgió a raíz del feminicidio de Diana Carolina a manos de un ciudadano venezolano el 19 de enero del 2019 frente a efectivos de la Policía Nacional. Este evento tuvo una serie de repercusiones que comenzaron con la destitución de la Gobernadora y del jefe de la Policía el 20 de enero de 2019. Asimismo, se generaron manifestaciones tanto en las 
ciudades de Ibarra como en Quito, organizadas por agrupaciones feministas en contra la violencia de género y la pasividad institucional. Paralelamente, también se dieron ataques contra la comunidad venezolana, en los que la Fundación Venezolanos en el Exterior "denunció que 82 compatriotas suyos han sido víctimas de agresiones xenofóbicas en distintas ciudades de Ecuador" (EFE, 2019). Hechos que enmarcaron el debate no en la restricción y control, sino que en el uso de atribuciones para la defensa ciudadana.

Ambos hechos marcarán un precedente respecto a los discursos que se habían ido registrando en los debates públicos sobre la acción policial, que ha permitido caracterizar ciertos elementos en común dentro de las posturas del debate, teniendo en cuenta que, como comentamos en el apartado anterior, muchas de las reparticiones y subdivisiones de la policía en Ecuador han estado fuertemente influenciadas por una lógica que busca la defensa del Estado y el despliegue eficiente de los aparatos coercitivos de la policía nacidos desde la doctrina de la enemigo interno instalada durante los años ' 80 .

En este marco, el secretario de comunicación de la presidencia de Ecuador, Andrés Michelena, declaró al día siguiente de los acontecimientos en Ibarra: "tenemos conocimiento de la estrategia de Maduro. No podemos tolerar que envíen a venezolanos que tienen detenidos en sus cárceles al Ecuador [sic]" (Globovisión, 2019). Así también las declaraciones del presidente Lenin Moreno: "les hemos abierto las puertas, pero no vamos a sacrificar la seguridad de nadie" (BBC, 2019)

El objetivo de estas declaraciones fue el de circunscribir el problema de la seguridad ciudadana a un lenguaje de invasión que permitiera justificar un aumento en el control policial sobre la inmigración. Misma táctica que sería utilizada en medio de las protestas ocurridas en el año 2019 por las reformas económicas emprendidas por el gobierno de Lenin Moreno, las que fueron inicialmente calificadas por actores gubernamentales como una serie de acciones de vandalismo producto de un "grupo de zánganos" (La Hora, 2019) y denunciadas como un plan de desestabilización impulsado por Rafael Correa, Nicolás Maduro, ex miembros de las FARC, los Latin King, y extranjeros venezolanos y cubanos. Frente al fracaso inicial de esta estrategia, el patrón comunicativo cambió: comenzó con la referencia a grupos indígenas como "nuestros hermanos", o el reconocimiento de que los indígenas son pacíficos, pero tienen "correístas" infiltrados - a nivel gubernamental, se ofrecieron a los indígenas subsidios para bonos agrícolas y proyectos de desarrollo comunitario-, y finalmente, lamentaron que entre los manifestantes hubiera "chavistas" y "miembros de las FARC" (Martín, 2019).

Estos intentos de acercamiento se dan en medio de un amplio rechazo por la desmedida violencia con las que se respondió a las protestas y los asesinatos cometidos por efectivos de la policía y el ejército, que entre sus varias repercusiones estuvo la organización de una comisión de investigación liderada por la defensoría del pueblo. En este sentido, es importante notar que esta retórica no sólo es utilizada para justificar las acciones del gobierno, sino que permiten posicionar en el debate público dos ideas fuerzas que son vitales para discutir las reformas policiales: en primer lugar, que las atribuciones que tienen las policías son insuficientes para cumplir con su cometido y, en segundo, que los mecanismos de control que están presentes son un impedimento para que se pueda restablecer el orden. Tal como señaló Fabian Fuel, director de operaciones del comando conjunto, "necesitamos que se revisen las leyes, necesitamos equipamiento. Esta inversión será en beneficio de un bien público: la seguridad de los ecuatorianos" (González, 2019).

Un examen que se puede hacer es observar la caracterización de los eventos cuando diferentes funcionarios de policía se ven involucrados en actos que constituyen delitos y/o 
crímenes de lesa humanidad. De esta forma, si se examinan los discursos políticos que emanan del gobierno de Lenin Moreno a través de la ministra de Gobierno, María Paula Romo, en el marco de las violaciones a derechos humanos perpetradas por efectivos de la policía nacional, la entonces ministra desarrolló una estrategia de comunicación basada en tres elementos para amparar la acción policial. El primero es la conversión del debido proceso en un juicio público. Esta estrategia no está destinada a establecer culpabilidades, ya que todas las aseveraciones que se realizan no necesariamente pueden ser comprobadas o imputadas a las víctimas, sino que se enfocan a convertir el proceso judicial en un juicio público en el que se asignan equipos que funcionan como un todo. No es sobre las personas que están de forma individual en el juicio, sino que los movimientos o instituciones que representan, tal como se puede apreciar en la siguiente cita de la ministra María Paula Romo, relacionada con el asesinato de José Chaluisa Cusco:

ese par de chicos venían de un incidente muy grave [...] habían quemado, habían vandalizado y habían incendiado un cuartel de policía, le metieron un patrullero dentro, la UVC 24 mayo, prendieron un patrullero dentro del cuartel, es decir con el patrullero forzaron las puertas, empujaron el patrullero hasta la mitad del cuartel. (Defensoría del Pueblo Ecuador, 2019)

Sin embargo, hasta el momento no existe una sentencia firme y ejecutoriada que sindique a José como culpable de dichos delitos. Otro caso que también ilustra esta estrategia, fueron las aseveraciones que se dieron en torno al asesinato de Édison Eduardo Mosquera:

En este caso hay una investigación ya en Fiscalía y en DINASED porque esta es una muerte producida por arma, pero un dato que es muy importante y que es relevante, es que este hecho se produjo en Cumandá, no se produjo en las zonas en donde había los enfrentamientos, o la actuación de la Policía. Y es el hermano de este señor quien lo lleva al Hospital del Sur. Este es un dato relevante para las investigaciones, para saber si se trata de una muerte violenta que sucedió en la ciudad de Quito, o si está de alguna manera relacionada con las manifestaciones. (Defensoría del Pueblo, 2019)

Sin embargo, como señaló el diario El Comercio (2019), Edison no tiene hermanos varones y se encontraron varios registros y relatos que prueban que hubo enfrentamientos entre protestantes y la Policía Nacional el 7 de octubre en el sector de Cumandá.

Estos comentarios, lejos de ser errores comunicacionales, se conectan con la idea de formar un juicio público entre los buenos - representados por las fuerzas del orden público-y, como el presidente Lenín Moreno dijo en un discurso, "la maldad representada por aquellos que desean únicamente hacer daño, lesionar" (Puente \& Díaz, 2020). Es este enfrentamiento enmarcado en binarios morales que permite el uso de la fuerza letal por parte de las policías "Disparen, señores, disparen porque solo en medio segundo existe la diferencia en que ustedes sean los héroes o no de la historia" (Redacción La República, 2020).

Esto intercepta el eje de las responsabilidades judiciales con un eje entendido a través de la moralidad que las instituciones públicas tratan de proyectar ante la imagen pública y que adjudican a movimientos sociales. De esta manera, se comienzan a forjar retóricas relacionadas con la guerra o con enfrentamientos binarios. 
Uno de los debates importantes a lo largo de las reformas policiales se encuentra en que organismos pueden aportar en el cumplimiento de la función policial; se debería crear un nuevo organismo de origen civil, cómo el título III del COESCOP, o se debería utilizar al ejército.

Como se observó en la sección anterior, este debate se ha inclinado por ceder este espacio al ejército, incluso llevando a graves conflictos con la función constitucional que a este se le concede.

La diferencia estándar también se puede encontrar en las palabras del ministro de defensa Jarrín con respecto al Servicio de Protección Pública. Lo que se pretende, dijo el ministro Oswaldo Jarrín, "es militarizar a la seguridad ciudadana: sería un grupo civil inconstitucional armado separado del Estado" (Ministerio de Defensa Nacional, 2018). En esta misma línea Cristina Reyes, miembro de la Asamblea Nacional de la República señala que:

la ley faculta al servicio de protección a solicitar apoyo de la policía o de las fuerzas armadas, cuando se presuma que el riesgo para el protegido es alto y sea necesaria la coordinación con dichas instituciones. Cuando se presenten estos casos, el nuevo cuerpo de protección liderará las actuaciones, es decir que las Fuerzas Armadas y la Policía se subordinan al mando de un Civil [...]. (Reyes, 2017)

Por el contrario, cuando se discute la integración de las fuerzas militares en labores propias de las policías, esta se plantea desde un reconocimiento de las capacidades y una defensa a los valores castrenses. Para esto, podemos destacar las palabras del ministro Jarrín, anteriormente opuesto a la militarización de los civiles, en el marco del debate por la suspensión por inconstitucionalidad del Acuerdo Ministerial 179, quien acotaría que:

Las Fuerzas Armadas no están divorciadas con la Sociedad y que el Acuerdo Ministerial 179 no impide la legítima protesta, al contrario norma la actuación de las Fuerzas Armadas cuando, en un estado de excepción, se les solicita participar en complementariedad con la Policía Nacional para realizar operaciones de control del orden público. (Ministerio de Defensa Nacional, 2020)

$\mathrm{Al}$ interior de estos argumentos podemos encontrar una valoración particular sobre el rol que los militares jugaron en las violaciones a los derechos humanos ocurridas. Dentro de estas argumentaciones podemos destacar las palabras del asambleísta Fernando Bustamante, en el marco de una presentación de la Ley de Seguridad:

yo creo que nadie excepto el más obcecado aquí va a decir que nuestras fuerzas tienen una tradición represiva que haga que tengamos que tener temor de su acción [...] no estamos en el cono sur en donde se cubrieron de sangre e ignominia, en este país solo esquemas dogmáticos alterados permiten pensar que las fuerzas armadas son una amenaza para el ciudadano. (Asamblea Nacional del Ecuador, 2011)

En este sentido, el principio axial sobre el que se encuentra este debate es la idea de que la seguridad interna de un país es, en alguna medida, similar a la función militar: la protección del orden de enemigos, en el caso de la policía internos y en el caso de la milicia externos. Es en esta comprensión que la integración de civiles se entiende como un riesgo a la seguridad, ya sea por falta de entrenamiento o susceptibilidad a la politización. 


\section{Conclusiones}

Al examinar tanto los procesos históricos como el debate que se ha generado en torno a las reformas policiales en los tres países, es posible visualizar que existen similitudes que dan cuenta de elementos estructurales que comporten los tres procesos de reformas estudiados, encontrando tanto elementos convergentes como divergentes

El primer elemento que surge del análisis histórico contextual es que cada una de las reformas inicia a través de un patrón similar: Un evento de abuso o corrupción por parte de funcionarios policiales desata una respuesta por parte de la sociedad civil que, mediante protestas, pone en entredicho al poder político; ahí es donde un ala del espectro político asume la necesidad de proponer una reforma con las características descritas en el marco teórico, mientras que la otra propone fortalecer las atribuciones otorgadas a los efectivos policiales. Es desde este debate que se comienzan a articular los discursos que estructuran las reformas.

Esta reactividad se nutre de una fuerte opacidad policial, puesto que gran parte de la crítica que se realiza a las policías se correlaciona directamente con una demanda generalizada de sancionar y actuar frente a los actos ilegítimos y arbitrarios que cometen las instituciones policiales, los cuales en muchos casos constituyen violaciones a derechos humanos, pues, tal como se mencionó, existe una complicidad entre el sector político y las instituciones policiales que permite que esto suceda,

Esta alianza, se vincula estrechamente con una construcción institucional heredera de la doctrina del enemigo interno, la cual une el uso de la violencia a una racionalidad particular respecto a la comprensión del crimen como un otro; la condición de criminal es una categoría esencial de quienes "rompen la ley", discurso que se aplica a situaciones tan diferentes como el fenómeno de la narco-economía como las manifestaciones. Esta otredad constituye un todo definido unilateralmente desde los discursos desde los sectores que "defienden el orden", cuya característica definitoria es la potencialidad del crimen. La construcción de esta potencialidad se hace en un espacio simbólico imaginario; no es lo que efectivamente han hecho y su coherencia con el corpus legal que regula el comportamiento; es que este comportamiento podría escalar en un futuro inevitable. Esta potencialidad inevitable se vuelve la justificación no solo para oponerse a las reformas, sino que para también apoyar y respaldar el actuar el uso arbitrario de las atribuciones policiales.

Otro aspecto importante en los discursos sobre las reformas es la defensa a la opacidad dentro de las instituciones policiales, en la medida en que se define al efectivo de policía como el único en posición de evaluar los procedimientos lo cual constituye una gran dificultad a la hora de proponer una reforma, en la medida en que estas son políticas públicas y requieren -al menosde un conocimiento necesario del cual nutrirse y generar las propuestas necesarias para alcanzar las metas que determinan su origen. En esta arista, la opacidad genera esta incapacidad de evaluar la acción policial tanto desde su efectividad como desde las consecuencias que esta tiene, generando una dicotomía contradictoria: Por un lado se requiere de un corpus de conocimiento que permita generar las reformas, sin embargo la institución repele, como describe Hathazy, (citado en Sirimarco, 2010) toda forma de observación y evaluación, situación que sólo puede romperse a través de una crisis institucional generada por un abuso de las atribuciones

Un segundo elemento convergente entre los tres países examinados es que, al momento de referirse a las reformas, el encuadre de este se hace desde una discursividad binaria que propone 
dos polos opuestos y excluyentes en términos de evaluar la actividad policial. El primero es la efectividad de los funcionarios policiales en el aseguramiento del orden, usualmente codificado a través del "respaldo a la institución", el "reconocimiento de su labor", "el uso de toda la fuerza de la ley" la lucha contra el "crimen", cuyo polo opuesto e irreconciliable es el cuidado de las garantías y los derechos humanos, incluso cuando estos se encuentran garantizados en las mismas leyes nacionales, el cual usualmente se presenta como una "defensa a los criminales".

Esta diada ha sido tremendamente efectiva para enmarcar los debates sobre políticas públicas de seguridad y las reformas policiales: En un ala del debate encontramos a actores políticos e institucionales que aceptan que los riesgos de la violencia policial son aceptables, por una miríada de razones, mientras que el que presentan las protestas sociales es totalmente inaceptable. Por otra parte, existe en este debate un sector que apoya las reformas policiales para frenar las malas prácticas institucionales, tomando en consideración que los casos de violaciones a los derechos humanos que han posicionado al debate no son casos aislados por parte de las instituciones, sino que son una práctica sistemática ${ }^{6}$ en donde los gobiernos centrales otorgan respaldo a las policías, centrando el apoyo en la labor policial frente a estas situaciones críticas y descalifica a las víctimas de sus acciones. Esto se evidencia también en la criminalización de los protestantes, puesto que se les considera parte del problema a la seguridad, reafirmando la presencia de un enemigo superior que justifica y promueve a su vez la estructura militar de las policías, en que cualquier intento de desmilitarizar y disminuir las prácticas de "mano dura" va en directa ayuda del enemigo superior.

En línea con lo anterior, existe un nivel de hostilidad hacia los organismos de derechos humanos nacionales e internacionales que denuncian o emprenden acciones para denunciar el abuso de las atribuciones policiales por parte de los efectivos. Esta práctica de deslegitimar organizaciones enteras se liga también hacia la de construir enemigos superiores, con escasa o ninguna evidencia real de la participación de estos, como suele ser el caso de los "agentes del gobierno venezolano" citados en el discurso de Lenín Moreno en el marco de las protestas en Ecuador o el "Enemigo Poderoso" invocado por Sebastián Piñera en las protestas del 18 de octubre.

Esta última tendencia se ancla a la herencia de la doctrina del enemigo interno, la cual se instaló a través de los gobiernos militares durante la guerra fría, la cual forjó un lazo entre las fuerzas militares y las fuerzas policiales, utilizando códigos legales, rangos y prácticas institucionales propias del ámbito castrense. Al mismo tiempo, hay con una alta desconfianza hacia la participación civil, encontrando varios registros en los que no sólo se duda de sus capacidades, sino que se advierte de un "riesgo ideológico", muchas veces sin ponderar la efectiva politización que han tenido históricamente las fuerzas militares y su rol en violaciones masivas a derechos humanos en sus respectivos países.

En términos generales, los intentos de reforma presentadas en Chile, Ecuador o Colombia no han podido generar grandes cambios estructurales, sino que siguen la misma línea de las modernizaciones que ya han tenido las policías. Esto se sigue enmarcando en la variante del modelo de policía comunitaria expuesto previamente por Labra, en el que no se ve la intención de generar un cambio radical al interior de la institución

\footnotetext{
${ }^{6}$ Para describir una conducta sistémica, se evalúan dos dimensiones. La primera es la existencia repetida y consistente de una conducta de violencia policial, una defensa corporativa a la acción de los efectivos infractores tanto a nivel judicial como comunicacional.
} 
El debate de la reforma a Carabineros y la Policía de Colombia y Ecuador ha sido complejo y ha estado marcado por numerosos actores que han instalado la demanda sobre la necesidad de un cambio estructural y fundamental al interior de las instituciones. Sin embargo, los encuadres discursivos con los que se abordan las reformas policiales vuelven este debate insalvable, favoreciendo fuertemente el status quo y generando prácticas de persecución contra ciudadanos y organizaciones que buscan defender los derechos humanos.

Queda por ver si en los futuros debates por las reformas institucionales a las policías y las políticas públicas relativas a la seguridad ciudadana se podrá superar la oposición, a nuestro juicio falsa, entre la seguridad y la garantía de los derechos humanos, principal obstáculo para que las reformas policiales puedan ganar tracción y se permita el avance hacia una policía respetuosa de los derechos humanos.

\section{Bibliografía}

ADN. (7 de octubre de 2020). El presidente Piñera reiteró su apoyo a Carabineros tras caso Pío Nono y llamó al Congreso a avanzar en el proyecto que moderniza la institución. www.adnradio.cl/politica/2020/10/07/presidente-pinera-reitero-su-apoyo-a-carabinerostras-caso-pio-nono-y-llamo-al-congreso-a-avanzar-en-el-proyecto-que-moderniza-lainstitucion.html

Asamblea Nacional del Ecuador. (19 de mayo de 2011). Sesión 103, Continuación intervención del asambleista Fernando Bustamante.

https://www.youtube.com/watch?app=desktop\&v=AV987lvaEhw\&feature=emb_title\&a b_channel=AsambleaNacionaldelEcuador

ASOFAR A.G. (2020). Declaración Pública ASOFAR A.G. http://www.cirjocar.cl/index.php/noticias/noticias-cirjocar/278-declaracion-publicareforma-a-carabineros

Badiola Heresmann, I. (2011). Función policial, democracia y accountability. Revista Logos, Ciencia \& Tecnología, 2(2). https://doi.org/10.22335/rlct.v2i2.96

Bailey, J., Parás, P., \& Vargas López, D. (2013). ¿El ejercito como policía? correlación de la confianza pública en la policía, el sistema judicial y los militares. Política y Gobierno, Volumen temático 2013, pp 161-185.

BBC. (21 de enero de 2019). Feminicidio en Ecuador: La advertencia del presidente Lenín Moreno a los migrantes venezolanos tras el asesinato de una mujer embarazada a manos de su expareja. BBC News.

Biblioteca del Congreso Nacional. (27 de febrero de 1990). Ley 18.961. Ley 18.961, Ley

Orgánica Constitucional de Carabineros de Chile. https://www.bcn.cl/leychile/navegar?idNorma=30329 
Bogotá, R. (2 de octubre de 2020). Encuesta ciudadana arroja que el $83 \%$ de los bogotanos quiere una reforma policial. Obtenido de El Espectador:

https://www.elespectador.com/noticias/bogota/encuesta-ciudadana-arroja-que-el-83-delos-bogotanos-quiere-una-reforma-policial/

Cambio21. (6 de febrero de 2021). Colegio de Periodistas (para rostros de la TV) por asesinato en Panguipulli: "No fue confuso incidente" o "enfrentamiento". Senadores y diputadas aseguran que "descontrol de Carabineros es criminal".

https://cambio21.cl/politica/colegio-de-periodistas-para-rostros-de-la-tv-por-asesinatoen-panguipulli-no-fue-confuso-incidente-o-enfrentamiento-senadores-y-diputadasaseguran-que-descontrol-de-carabineros-es-criminal-601e07e7aa2d7453d31da4ac

Camacho, A. (2000). La policía colombiana. Los recorridos de una reforma. Análisis Político (41), 99-118. Obtenido de https://revistas.unal.edu.co/index.php/anpol/article/view/80033

Casas, P. (2005). Reformas y contrarreformas en la policía colombiana. Seguridad urbana y policía en Colombia, 1-80.

CIPER Chile. (23 de 12 de 2019). ¿Por qué Colombia está marchando? http://www.ciperchile.cl/2019/12/23/por-que-colombia-esta-marchando/ . (15 de Julio de 2020). Balance penal del estallido: Fiscalía investiga a 466 agentes del Estado y gobierno acusa a 3.274 personas de cometer actos violentos. https://www.ciperchile.cl/2020/07/15/balance-penal-del-estallido-fiscalia-investiga-a466-agentes-del-estado-y-gobierno-acusa-a-3-274-personas-de-cometer-actos-violentos/

CNN. (11 de septiembre de 2020). Javier Ordóñez: la indignación en Colombia por la muerte de un hombre tras una violenta detención de la policía por violar la cuarentena. Obtenido de BBC MUNDO: https://www.bbc.com/mundo/noticias-america-latina-54095677

CNN Chile. (9 de octubre de 2020). "El presidente confunde la reforma a Carabineros con otras reformas sobre problemas de seguridad". Obtenido de https://www.cnnchile.com/pais/expertos-critican-anuncio-pinera-reformacarabineros_20201009/

. (19 de noviembre de 2020). Heraldo Muñoz propone que el PPD congele con el gobierno tras disparos a niños del Sename. https://www.cnnchile.com/pais/heraldomunoz-ppd-congelar-relaciones-gobierno-disparos-ninos-sename_20201119/

Comisión de la Verdad Ecuador. (2010). Sin Verdad no hay Justicia. Quito.

Consejo Asesor Reforma Carabineros. (enero de 2020). Consejo Reforma a Carabineros. Obtenido de https://cdn.digital.gob.cl/filer public/52/fe/52fe7434-e81b-48b9-b31479cd56ce134f/consejo_carabineros_v2.pdf

Consejo Asesor Reforma a Carabineros. (2020). Consejo de Reforma a Carabineros. Santiago.

Consejo Nacional Electoral. (2017). Resultados de la Consulta Popular. Obtenido de http://app2.cne.gob.ec/resultados/resultadosn.aspx

Constitución de la República del Ecuador. (20 de octubre de 2008). Artículo N$^{\circ} 279$. Quito.

Cruz-Rodríguez, E. (2017). El postconflicto y la reforma de la policía colombiana: el problema de la desmilitarización. Memorias, 15-27.

Dammert, L. (2005). Reforma Policial en América Latina. Quórum. Revista de pensamiento iberoamericano, 53-64. Obtenido de https://www.redalyc.org/pdf/520/52001205.pdf . (23 de 10 de 2020). El lado oscuro de las dos policías ejemplares de Latinoamérica. Obtenido de CIPER: https://www.ciperchile.cl/2020/10/23/el-lado-oscuro-de-las-dospolicias-ejemplares-de-latinoamerica/ 
Defensoría del Pueblo Ecuador. (2019). Expediente CEVJ-210-CCJD. Quito. . (2019). Séptimo informe ejecutivo de personas detenidas en el paro nacional-estado de excepción octubre 2019. Quito. . (2019). Demanda en contra del Estado de Ecuador 2019. Quito.

Diario U chile. (2019 de noviembre de 2020). Hasta que se derramó el vaso: Mario Rozas renuncia a la dirección de Carabineros. https://radio.uchile.cl/2020/11/19/hasta-que-sederramo-el-vaso-mario-rozas-renuncia-a-la-direccion-de-carabineros/

EFE. (21 de enero de 2019). Un feminicidio desata temor a una oleada xenófoba contra venezolanos en Ecuador. Agencia EFE.

El Comercio. (28 de septiembre de 2011). 30S Insubordinación Policial. https://especiales.elcomercio.com/2011/09/30s/

El Espectador. (11 de diciembre de 2020). La denuncia que se viene en contra del ministro de Defensa por las protestas del 9S. https://www.elespectador.com/noticias/judicial/ladenuncia-que-se-viene-en-contra-del-ministro-de-defensa-por-las-protestas-del-9s-enbogota/

El Mostrador. (31 de enero de 2020). El doloroso balance de la Fiscalía sobre las víctimas en el estallido: 31 muertos y 5.558 personas han denunciado violaciones de DD.HH. El Mostrador. https://www.elmostrador.cl/noticias/pais/2020/01/31/el-doloroso-balancedel-ministerio-publico-sobre-las-victimas-en-el-estallido-31-muertos-y-5-558-personasdenuncian-violaciones-de-dd-hh/

. (10 de febrero de 2021). Ministra Karla Rubilar quiere más que una reforma: "Sería vital tener una suerte de refundación de Carabineros".

https://www.elmostrador.cl/dia/2021/02/10/ministra-karla-rubilar-quiere-mas-que-unareforma-seria-vital-tener-una-suerte-de-refundacion-de-carabineros/

El Tiempo. (19 de diciembre de 2019). ¿Por qué el caso de Dilan Cruz pasó a la justicia penal militar? https://www.eltiempo.com/justicia/cortes/por-que-el-caso-por-muerte-de-dilancruz-paso-a-la-justicia-penal-militar-445186

. (24 de septiembre de 2019). Qué pasó con las investigaciones de la comunidad del anillo. https://www.eltiempo.com/justicia/delitos/que-paso-con-las-investigaciones-porla-comunidad-del-anillo-415932

. (21 de septiembre de 2020). El pulso que viene en el Congreso por reformas a la Policía. https://www.eltiempo.com/politica/congreso/reformas-a-la-policia-nacionalpulso-en-el-congreso-538906

El Universo. (17 de agosto de 2020). Corte analiza constitucionalidad de tres normas más relacionadas con el uso de la fuerza militar en manifestaciones.

Emol. (6 de febrero de 2021). Oposición reitera llamado a refundar Carabineros tras muerte de joven en Panguipulli: "El país necesita una nueva policía".

https://www.emol.com/noticias/Nacional/2021/02/06/1011513/Oposicion-Panguipullirefundar-Carabineros-policia.html

Frühling, H. (2006). Prevención como política pública y experiencia local. + comunidad, + prevención. Centro de Estudios en Seguridad Pública, (5), 1-23.

Galeano. (2007). En nombre de la seguridad: Lecturas sobre policía y formación estatal. Cuestiones de Sociología, 4(4), 102-125.

http://www.memoria.fahce.unlp.edu.ar/art_revistas/pr.3679/pr.3679.p

García, A. (24 de junio de 2020). Corte Constitucional suspendió acuerdo sobre uso progresivo de la fuerza, emitido por el Ministerio de Defensa. El Comercio. 
Garretón, M. A. (septiembre de 1995). Encuentro Académico Sobre Reconciliación y Democracia. Consejo de Rectores de Universidades Chilenas, 92-93.

Globovisión. (21 de enero de 2019). "No podemos tolerar que envíen a venezolanos que tienen detenidos en sus cárceles al Ecuador".

González, M. (4 de diciembre de 2019). Manual para acción militar en las calles se ajusta para la insurgencia. Primicias.

Hathazy, P. (2009). Expertos, burócratas y política en la transformación de carabineros de Chile. Buenos Aires.

. (2010). Los caminos de la opacidad: Accesibilidad y resistencia en el estudio de las organizaciones policiales como obstáculo y dato. En M. Sirimarco (Ed.), Estudiar la policía. Teseo.

. (2016). Democratización y campo policial. Civitas, 595-617.

Infobae. (3 de octubre de 2020). Conmoción en Chile por un menor que fue lanzado al río por un carabinero durante una protesta. Obtenido de https://www.infobae.com/america/america-latina/2020/10/03/conmocion-en-chile-porun-menor-que-habria-sido-lanzado-al-rio-durante-protesta/

Jarrin, R. (1991). El Cementerio de los Vivos. Quito: Ediciones C.T.E.

Jerez, D. (10 de septiembre de 2020). Tras caso de abuso, ¿se debe reformar la Policía Nacional? Obtenido de RCN: https:/www.rcnradio.com/politica/tras-caso-de-abuso-se-debereformar-la-policia-nacional

Judicial, R. (11 de diciembre de 2020). La denuncia que se viene en contra del ministro de Defensa por las protestas del 9S. Obtenido de El Espectador:

https://www.elespectador.com/noticias/judicial/la-denuncia-que-se-viene-en-contra-delministro-de-defensa-por-las-protestas-del-9s-en-bogota/

Kast, J. [@jakast] (12 de octubre de 2020). No se necesita una reforma a Carabineros. Se necesita mano firme contra el vandalismo, el narcotráfico, el terrorismo y la delincuencia, ¡basta de cobardía! [Tuit]. Twitter. https://twitter.com/joseantoniokast/status/1315802377212043264?lang=es

Kozma, T. (2014). Partnership for Peace Consortium of Defense Academies and Security Studies Institutes from Adjusting to Rebuilding Police Institutions. Partnership for Peace Consortium of Defense Academies and Security Studies Institutes, XIII (3), 117-123. Obtenido de https://www.jstor.org/stable/10.2307/26326371

La Hora. (4 de octubre de 2019). Moreno: ni con zánganos ni delincuentes.

La Tercera. (19 de noviembre de 2020). Talcahuano: operativo de Carabineros en hogar del Sename termina con dos menores baleados. https://www.latercera.com/nacional/noticia/talcahuano-operativo-de-carabineros-enhogar-del-sename-termina-con-dos-menoresbaleados/XD4ZGLPW2RHXJHVBYYP6DT63I4/

La República. (7 de febrero de 2020). Cynthia exhorta a los policías a disparar contra delincuentes.

Labra, C. (2011). El modelo de policía comunitaria: El caso chileno. Revista Chilena de Derecho y Ciencia Política, 3(1), 49-61.

Legnani, N. (2007). La Modernización Policial en la Argentina y el Rol de lo Educativo. Sociedad Global, 36-51.

Martín, S. (11 de octubre de 2019). Lenín Moreno: Protestas en Ecuador están infiltradas por FARC y chavistas. Panam Post. 
Meganoticias. (18 de noviembre de 2020). Unicef condena actuar de Carabineros en caso de menores del Sename heridos en Talcahuano.

https://www.meganoticias.cl/nacional/319414-unicef-condena-actuar-carabineros-casomenores-heridos-sename-talcahuano-ndx18.html

Ministerio de Defensa Nacional. (4 de julio de 2018). Sitio Oficial del Ministerio de Defensa. Obtenido de https://www.defensa.gob.ec/min-jarrin-el-servicio-de-proteccion-publicano-es-constitucional/

. (5 de junio de 2020). Sitio oficial del Ministerio de Defensa Nacional. Obtenido de https://www.defensa.gob.ec/el-ministro-de-defensa-nacional-comparece-en-la-comisionde-soberania-de-la-asamblea-nacional-para-explicar-el-acuerdo-ministerial-179/

Ministerio de Hacienda. (2006). Programa Plan Cuadrante de Seguridad Preventiva. Informe final de evolución. Santiago: Ministerio de Hacienda. Dirección de Presupuesto.

O’Donell, G. (2002) Acerca de Varias accountabilities y sus interrelaciones; en Peruzotti, E; Gervasoni, C. Smulovitz, C. (Ed.) Controlando la política. Ciudadanos y medios en las nuevas democracias latinoamericanas, 87-102.

Oviedo, E. (2007). Modernización policial: El caso de carabineros de Chile. Revista Latinoamericana de Seguridad Ciudadana, (2), 71-84.

Piedrahita, P. (26 de septiembre de 2020). Uso excesivo de la fuerza y derechos humanos: casos de Chile y Colombia [video]. YouTube. Obtenido de https://www.youtube.com/results?search_query=uso+excesivo+de+la+fuerza+en+colom bia $+y+$ chile

Policía de Investigaciones de Chile. (2009). Logros de la Modernización. Obtenido de PDI: https://www.pdichile.cl/cuentapublica/2010/web/logros.html\#: :text=La\%20modernizac i\%C3\%B3n\%20de\%20la\%20PDI,justicia\%2C\%20en $\% 20 \operatorname{sinton} \% \mathrm{C} 3 \% \mathrm{ADa} \% 20$ con $\% 20$ las

Pontón, D. (2014). El proceso de reforma policial en Ecuador: un tema relegado al olvido. URVIO, Revista Latinoamericana de Estudios de Seguridad, 451 - 480. . (2018). Policía y revolución ciudadana: un balance de la politica policial en Ecuador 2007-2014. Delito y Sociedad, 75-118.

Puente, D., \& Díaz, V. (octubre de 7 de 2020). Policías que acorralaron a varias personas en el puente de San Roque, durante el paro, son investigados por homicidio en el caso de Daniel Chaluisa. El Comercio.

Reyes, C. (2017). Oficio Nº02-CRG-AN-2017. Quito.

RCN. (10 de septiembre de 2020). Tras caso de abuso, ¿se debe reformar la Policía Nacional? https://www.rcnradio.com/politica/tras-caso-de-abuso-se-debe-reformar-la-policianacional

Saboya Vargas, F. (2006). La modernización del Estado: concepto, contenido y aplicaciones posibles. Revista uni libre. Diálogos de Saber, 257-376.

Schedler, A. (1999). ¿Qué es la rendición de cuentas? En A. Schedler, L. Diamond, \& M. Plattner, The Self-Restraining State: Power and Accountability in New Democracies (págs. 13-28). Obtenido de http://www.infodf.org.mx/capacitacion/documentos/JURIDICO08/LECTURAS/MODU LO\%202/RENDICIONDECUENTAS.pdf

Semana. (15 de septiembre de 2020). ¿Es hora de una reforma a la Policía? Los proyectos de ley que la proponen. https://www.semana.com/nacion/articulo/los-proyectos-de-ley-queproponen-reformas-la-policia-elfuturodelapoliciaes/702582/ 
Siavelis, P. (2009) Enclaves de la Transición y Democracia Chilena. Revista de Ciencia Política, 3-21. extraído desde https://www.scielo.cl/pdf/revcipol/v29n1/art01.pdf

Sirimarco, M. (Comp) (2010). Estudiar la policia: Las miradas de las ciencias sociales sobre la institucion policial. Buenos Aires: Teseo.

Stange Oelckers, R. (1995). Exposición del General Director con motivo del 68 aniversario de Carabineros. 7-23.

Teletrece. (11 de octubre de 2020). José Antonio Kast: "El gobierno ha cometido más errores que todos los carabineros juntos”.' https://www.t13.cl/noticia/politica/jose-antonio-kastgobierno-ha-cometido-mas-errores-todos-carabineros-juntos . (5 de febrero de 2021). Malabarista muere baleado por carabinero tras incidente en fiscalización en el centro de Panguipulli. https://www.t13.cl/noticia/nacional/malabarista-muere-baleado-carabineros-panguipulli05-02-2021 